Harald W. Lang

\title{
You Are Not Alone: Experimental Evidence on Risk Taking When Social Comparisons Matter
}

Max Planck Institute for Tax Law and Public Finance Working Paper 2016 - 12

November 2016

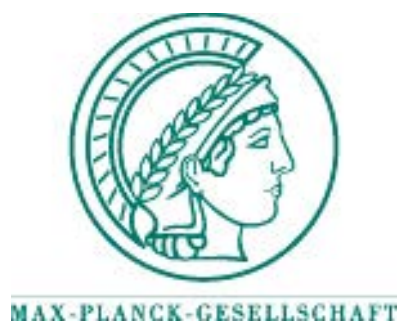

Max Planck Institute for Tax Law and Public Finance

Department of Business and Tax Law

Department of Public Economics

http://www.tax.mpg.de 
Working papers of the Max Planck Institute for Tax Law and Public Finance Research Paper Series serve to disseminate the research results of work in progress prior to publication to encourage the exchange of ideas and academic debate. Inclusion of a paper in the Research Paper Series does not constitute publication and should not limit publication in any other venue. The preprints published by the Max Planck Institute for Tax Law and Public Finance represent the views of the respective author(s) and not of the Institute as a whole. Copyright remains with the author(s).

Max Planck Institute for Tax Law and Public Finance

Marstallplatz 1

D-80539 Munich

Tel: $\quad+498924246-0$

Fax: $\quad+498924246-501$

E-mail:ssrn@tax.mpg.de

http://www.tax.mpg.de 


\title{
You are not alone: Experimental evidence on risk taking when social comparisons matter
}

\author{
Harald W. Lang*
}

November 24, 2016

\begin{abstract}
We provide experimental evidence that social comparisons affect individual risk taking. In particular, we focus on the case when individuals care about their income-rank. Our model predicts that compared to standard expected utility theory income-rank comparisons lead to less (more) risk taking in case of lotteries with more probability mass on the downside (upside) of the distribution. Evidence shows in line with our predictions that individuals take less risk when lotteries have more probability weight on the downside. However, we do not find an effect for lotteries with more upside probability mass. The effect of social comparisons on risk taking is strongest when the deciding subject and the reference subject are of the same gender.
\end{abstract}

JEL codes: C91, D03, D81, G11.

Keywords: Social comparisons, individual risk taking, status, portfolio choice, relative income concerns, experiment.

\footnotetext{
*Max Planck Institute for Tax Law and Public Finance. E-mail: harald.lang@tax.mpg.de
} 


\section{Introduction}

Since Veblen (1899) economists have considered income comparisons to be an important objective for individuals that yields manifold implications in economics. While theorists extended the analysis of income comparisons to its consequences for taking risk (e.g., Robson 1992, Konrad and Lommerud 1993, Becker et al. 2005) less empirical evidence has since followed. We contribute to the literature by investigating the case of income-rank comparisons in a laboratory experiment. Our theoretical predictions show that, compared to standard expected utility theory, income-rank comparisons lead to less (more) risk taking in case of lotteries with more downside (upside) probability mass. Overall, we find that individuals respond in their risk taking to comparison concerns. Individuals take less risk when lotteries have more probability weight on the downside. However, we do not find an effect for lotteries with more upside probability mass. Individuals respond more strongly to comparison concerns when reference subjects are of the same sex.

The economic outcomes of others matter for individuals in many contexts (e.g., Sobel 2005, Fehr and Schmidt 2006). However, empirical research did not embrace the interaction of social comparisons and decisions under uncertainty until relatively recently even though decisions involving risk usually take place in a social context. ${ }^{1}$ Individuals usually face decisions on pursuing personal education, choosing an occupation, making savings or financial investment decisions while being aware of the situation of others. Consider an investor facing the decision on how to allocate his savings to financial investment opportunities. He could invest a major part of his funds in risky stocks or rather in a low return but safe savings account. While his investment choice will impact his future consumption, at the same time, his investments will have implications for his relative income position, for instance, relative to his sparkish brother-in-law. Higher financial risk might offer the chance to do better or fall behind in terms of income. As the investor of this example, we are not alone in this world but we have siblings, colleagues, friends, and neighbors. When we feel comparison concerns toward one or the other it seems natural that we incorporate not only the implications for the absolute but also for the relative income into our risk taking decisions.

To investigate the effect of comparisons on risk taking, we first need to take a stand in which form comparison concerns enter the individual utility. One possibility is that individuals care about their rank in the income distribution, as first formalized by Frank (1985b), thereby assuming that comparison concerns are intrinsically ordinal. ${ }^{2}$ Alternatively,

\footnotetext{
${ }^{1}$ Early experimental papers on social concerns and risk taking investigate, for instance, procedural fairness (e.g., Bolton et al. 2005, Krawczyk and Le Lec 2010) or the relationship of other regarding concerns and risk attitudes (e.g., Brennan et al. 2008, Güth et al. 2008). For an overview of the literature on social concerns and risk attitudes see Trautmann and Vieider (2012).

${ }^{2}$ Also, see Frank (2013) for applications of utility that is dependent on the rank relative to others beyond
} 
the distance between the own income and the income of others might enter the utility, implying that income comparison concerns are cardinal. ${ }^{3}$ While the empirical literature generally finds that individuals care about income comparisons (see, e.g., Easterlin 1995, Clark and Oswald 1996, McBride 2001, Ferrer-i-Carbonell 2005, and Luttmer 2005) few studies refer to a possible difference between comparison considerations based on the rank in the income distribution and the distance in income to others. ${ }^{4}$ In the following, we focus on income-rank comparisons but address preferences for the distance in incomes in an additional treatment.

Robson (1992) and Konrad and Lommerud (1993) are the first to theoretically analyze the impact of social comparisons on risk attitudes. The former study assumes income-rank comparisons while the latter models income comparisons as the distance between incomes. Following Robson (1992) we rely on income-rank comparisons to derive theoretical hypotheses. Inspired by Konrad's and Lommerud's (1993) distinction hat the correlation structure of own risks with risks of others can matter, we analyze in our baseline scenario an environment where the risk of individuals is perfectly correlated. In an additional treatment we vary the correlation structure and investigate the case of uncorrelated risk.

At first sight, the effect of income-rank comparisons on risk taking behavior is not obvious and one might come up with examples concluding that income-rank comparisons simply induce more risk taking (e.g., Frank 2008, p. 1778). We show that the properties of the respective probability distribution of a lottery are crucial factors. Compared to standard expected utility theory subjects are expected to take more risk in case of lotteries with more upside probability mass but less risk in case of more probability weight on the downside. Intuitively, individuals shift more income to the state of the world that is more likely to materialize so that they are more likely to be ahead in income-rank once this state does materialize. We apply these predictions to empirically test the effect of income-rank comparisons on risk taking.

An empirical analysis of the impact of social comparisons on individual decisions is intrinsically difficult in the field. The controlled environment in the laboratory allows us to focus on a clean isolation of the effect of comparison concerns on risk taking. We can com-

monetary wealth or income.

${ }^{3}$ The assumption that individuals care about the distance in incomes was first formalized by Duesenberry (1949) (see Clark et al. 2008 for an overview of the literature). Note that the choice to apply the distance or the rank in income has an impact on the results in many theoretical applications (Bilancini and Boncinelli 2008).

${ }^{4}$ One exception is a study by Clark et al. (2009). They find that a lower rank in the local income distribution of a neighborhood relates negatively to subjective well-being. However, conditional on the personal income, having richer neighbors shows a positive effect. Clark et al. (2009) argue that having rich rather than poor neighbors provides other positive externalities than implied by relative standing concerns. These positive externalities could explain the positive effect of richer neighbors on subjective well-being. 
pare situations, in which we eliminate income comparisons to the greatest possible extent, to similar situations, in which we expect income comparisons. In the experiment, subjects face classical portfolio choice decisions where they allocate their endowment between a risky lottery and a risk-free investment opportunity. The risky lotteries differ in terms of upside and downside probability mass (i.e., whether a gain or loss is more likely) but offer identical expected returns. In the baseline treatment "Alone" subjects face portfolio choices while being alone in the laboratory so that income comparisons should not be of any immediate concern. In the reference treatment "Social" subjects enter the laboratory in groups of two and simultaneously face the same portfolio choices as the other participant. The change in the share of the endowment that subjects invest into the risky lottery, comparing treatments Alone and Social, allows us to investigate the effect of income comparisons on risk taking. Both treatments Alone and Social are identical except for the present second participant. Importantly, subjects neither observe decisions nor earnings of the other participant nor do they interact, so that we can rule out other peer effects.

We find evidence of an effect of income comparisons on risk taking. In line with our theoretical predictions, individuals take less risk for lotteries with more downside probability mass. However, we do not find a significant effect in the case of more upside probability weight. We test whether this asymmetric finding can be explained by other forms of comparison concerns, such as a preference for the distance in incomes à la Konrad and Lommerud (1993) or social loss aversion. To do so we run an additional treatment in which income risk is uncorrelated among participants. Consequently, we increase the risk for the relative income position while we leave the risk for the personal income unchanged. In contrast to preferences for the distance in incomes and social loss aversion we find that the effect of comparisons on risk taking turns out to be similar but weaker in the additional treatment. Furthermore, for all treatments holds that the effect of comparison considerations on risk taking is predominantly present in situations where the reference subject is of the same sex as the deciding subject. Thus, attributes of reference subjects are a crucial piece of the picture and Festinger's (1954) idea of social comparisons being stronger among more similar individuals seems to extend to the income and risk taking dimension.

We contribute to a small but growing number of experimental studies that are inspired by social comparisons and risk taking. ${ }^{5}$ These studies generated partly contradicting results.

\footnotetext{
${ }^{5}$ Comparison concerns are effectively a form of peer effects and our work also relates to the literature on peer effects under uncertainty (e.g., Bougheas et al. 2013, Cooper and Rege 2011, Viscusi et al. 2011). In this strand of the literature the work of Lahno and Serra-Garcia (2015) is closest to us. They investigate peer effects in a binary lottery choice setting and find that the probability to switch a previous stated lottery choice can be explained by concerns about the observed choices of other individuals and by relative payoff concerns.
} 
For instance, Rohde and Rohde (2011) do not find evidence of social comparisons affecting risk taking. However, applying physiological measures, Bault et al. (2008) and Bault et al. (2011) find that lottery outcomes do affect subjects differently for different lottery outcomes of others. They find that social gains lead to stronger responses than social losses. Focusing directly on risk taking behavior, Linde and Sonnemans (2012) find that subjects take less risk when they can win at most as much as a certain payoff of a reference subject (social loss situation) compared to the case when they can win at least as much as a reference subject (social gain situation). In contrast to Linde and Sonnemans, Schwerter (2013) finds that subjects take more risk when they observe a higher rather than a lower certain payoff of others, in order to surpass or to stay ahead of others. Consequently, Schwerter interprets his results in favor of social loss aversion while Linde and Sonnemans argue that their findings suggest that loss aversion does not easily extend to the case of social comparisons. ${ }^{6}$ Motivated by the insurance market, Friedl et al. (2014) find experimental evidence that social comparisons make insurance policies less attractive when risks are correlated. Dijk et al. (2014) focus on rank-comparisons and performance pay and apply a dynamic setting where subjects accumulate investment returns over several rounds. They find evidence that underperformers adjust their investments toward positively skewed assets while over-performers adjust their investments toward negatively skewed assets. This holds similarly for situations when subjects only observe the performance of others, and for situations when individuals are actually paid according to their relative performance.

The setup of this paper deviates from the previous studies in important aspects. First, in our experiment, subjects neither observe decisions of others (as in many peer effect studies) nor what others earn (as, for instance, in Linde and Sonnemans 2012, Schwerter 2013 or Dijk et al. 2014). The former point is important to control for any sort of peer effect that is not related to comparison concerns, the latter feature ensures that subjects do not adjust expectations about likely experimental earnings when they observe earnings of others before they make their decisions. Second, while other studies vary payoffs or lotteries of reference subjects when social comparison concerns are at work, we identify the effect of comparisons on risk taking by comparing situations with social comparisons to situations without social comparisons. Third, in contrast to other studies we apply a classical portfolio choice setting. ${ }^{7}$ Finally, while for many studies the theoretical starting point is an extension of Kahneman's and Tversky's (1979) prospect theory to the social dimension, we focus on income-rank

\footnotetext{
${ }^{6}$ Recently, Grimm et al. (2015) also find evidence that individuals more often choose more risky decisions when they are in a disadvantaged initial position relative to another party.

${ }^{7}$ In the experimental literature a portfolio choice setup to investigate risk taking was first introduced by Gneezy and Potters (1997) and has been applied in different contexts (e.g., Sutter 2007, Charness and Gneezy 2010).
} 
comparisons and subsequently analyze whether other forms of social comparisons, such as social loss aversion, can explain our results. ${ }^{8,9}$

\section{Framework}

\subsection{Risk taking and income-rank comparisons}

Consider a model with two individuals $i \in\{1,2\}$. Individuals care about absolute income $y_{i} \in \mathbb{R}_{+}$and the rank in income. Their utility function exhibits the following form:

$$
\begin{aligned}
U & =u\left(y_{i}\right)+S\left(y_{i}, y_{-i}\right), \\
\text { with } S(\cdot) & =\left\{\begin{array}{ll}
W & \text { if } y_{i}>y_{-i} \\
0 & \text { if } y_{i}=y_{-i} \\
L & \text { if } y_{i}<y_{-i}
\end{array} \text {, where } W>0>L .\right.
\end{aligned}
$$

While the part $u\left(y_{i}\right)$ represents a standard (consumption) part of the utility function $S\left(y_{i}, y_{-i}\right)$ adds a positive, negative or zero utility value depending on the relative income position to the other individual $-i$. Income $y_{i}$ depends on the endowment $E$ that is identical for individuals and normalized to one, and on $i$ 's investment decision of allocating $E$ across a risky and a risk-free investment opportunity. The risky investment offers a return $\theta_{G}>1$ with a probability $p_{G}$ and a return of $\theta_{B}=0$ with a probability $1-p_{G}$ that is perfectly correlated for both subjects. The risk-free investment allows individuals to store income at zero costs (return of 1 ). We assume that $p_{G} \theta_{G}>1$ holds at any time to keep the problem non-trivial in the case of risk aversion. Defining $a_{i}$ as share of $E$ invested into the risky project, expected income is

$$
E\left(y_{i}\right)=1+\left(p_{G} \theta_{G}-1\right) a_{i}
$$

As we focus on the effect of income-rank-dependent utility on risk taking decisions, we abstract from strategic interaction between individuals to simplify the analysis. Thus, we

\footnotetext{
${ }^{8}$ Note that the results of the studies investigating social loss aversion do not necessarily disagree with income-rank comparisons (e.g., Schwerter's 2013 results seem to be in line with income-rank-dependent preferences).

${ }^{9}$ The effect of preferences for distributional fairness (i.e., people dislike inequity) on risk taking also attracted some interest in the literature. Recently Bolton et al. (2015) find no evidence that social risk taking is driven by this type of preferences. Other studies that investigate social risk taking and whose results do not fit social preferences for distributional fairness include Bereby-Meyer and Roth (2006), Güth et al. (2008), Brennan et al. (2008), Bolton and Ockenfels (2010) and Cappelen et al. (2013).
} 
assume that individual 1 actively chooses the share of risky investment $a_{1}$, while individual 2 is passive in the sense that $a_{2}$ is randomly drawn from a continuous uniform probability distribution $F\left(a_{2}\right)$ with a corresponding probability density function $f\left(a_{2}\right)$. The active individual faces the following maximization problem:

$$
\max _{a_{1}} E\left[u\left(y_{1}\left(a_{1}\right)\right)+S\left(y_{1}\left(a_{1}\right), y_{2}\left(a_{2}\right)\right)\right]
$$

Abstracting from $S\left(y_{1}, y_{2}\right)$ for a moment and only considering the standard part of the utility function $E\left[u\left(y_{1}\left(a_{1}\right)\right)\right]$, it is straightforward to derive an optimal share $a_{1}^{*}$ that depends on risk preferences when we rely on standard assumptions with respect to $u(\cdot)$. Starting from $a_{1}^{*}$ the question of interest can be reformulated as follows: How does risk taking, i.e. the optimal choice of $a_{1}$, change when the income comparison part $S\left(y_{1}, y_{2}\right)$ enters the situation? This can be done by considering the following trade-off: adjusting $a_{1}$ away from $a_{1}^{*}$ causes costs related to the standard part of the utility function, $u\left(y_{1}\left(a_{1}\right)\right)$, but offers the chance to gather an income comparison gain (or loss) due to $S\left(y_{1}, y_{2}\right)$. Starting from the optimum without income comparisons, $a_{1}^{*}$, we can define the costs of deviating from $a_{1}^{*}$ as

$$
C\left(a_{1}\right)=E\left[u\left(y_{1}\left(a_{1}^{*}\right)\right)\right]-E\left[u\left(y_{1}\left(a_{1}\right)\right)\right]
$$

where the first term on the right-hand side is a constant representing the utility level of the standard part of the utility function given the optimal $a_{1}^{*} \cdot{ }^{10}$ It follows that $C\left(a_{1}^{*}\right)=C^{\prime}\left(a_{1}^{*}\right)=$ 0 as a minimum, $C^{\prime}\left(a_{1}\right)>0$ if $a_{1}>a_{1}^{*}$ and $C^{\prime}\left(a_{1}\right)<0$ if $a_{1}<a_{1}^{*}$. A sufficient condition for this cost function to be convex, $C^{\prime \prime}\left(a_{1}\right)>0$, is that $u\left(y_{1}\left(a_{1}\right)\right)$ is strictly concave, and thus, that individuals are risk averse. ${ }^{11,12}$ The maximization problem of individual 1 can be reformulated to

$$
\begin{aligned}
\max _{a_{1}} \pi_{1}= & p_{G} \times\left[F\left(a_{1}\right) W+\left(1-F\left(a_{1}\right)\right) L\right] \\
& +\left(1-p_{G}\right) \times\left[F\left(a_{1}\right) L+\left(1-F\left(a_{1}\right)\right) W\right]-C\left(a_{1}\right) .
\end{aligned}
$$

The income comparison gain or loss for individual 1 in (6) is determined by the outcome of the risky investment and by the personal share invested into the risky asset $a_{1}$ relative to the other individual's share $a_{2}$. Note that both individuals face a perfectly correlated

\footnotetext{
${ }^{10}$ Note that we define $C(\cdot)$ in utils rather than pecuniary certainty equivalents. Although this approach seems a bit unconventional, it proves to be constructive for our purpose.

${ }^{11}$ For a derivation of the sufficient condition for the convexity of $C(\cdot)$ see Appendix B.1.

${ }^{12} \mathrm{We}$ assume from now on that individuals are risk averse in the standard part of the utility function (i.e. $u\left(y_{1}\left(a_{1}\right)\right)$ is strictly concave).
} 
investment project, and thus, both individuals will end up receiving simultaneously the return $\theta_{G}$ in the good state or a return of 0 in the bad state. Therefore, in the good state individual 1 will gain comparison utility $S^{1}\left(y_{1}\left(a_{1}\right), y_{2}\left(a_{2}\right)\right)=W$ iff $a_{1}>a_{2}$ and lose utility $S^{1}\left(y_{1}\left(a_{1}\right), y_{2}\left(a_{2}\right)\right)=L$ iff $a_{1}<a_{2}$. Analog, in the bad state $S^{1}\left(y_{1}\left(a_{1}\right), y_{2}\left(a_{2}\right)\right)=L$ iff $a_{1}>a_{2}$ and $S^{1}\left(y_{1}\left(a_{1}\right), y_{2}\left(a_{2}\right)\right)=W$ iff $a_{1}<a_{2}$. Solving problem (6) yields the first-order condition

$$
f\left(a_{1}^{s}\right)[W-L]\left[2 p_{G}-1\right]=C^{\prime}\left(a_{1}^{s}\right) .
$$

When the left-hand side of $(7)$ is larger than zero, $C^{\prime}\left(a_{1}^{s}\right)$ must be positive, and hence, the optimal share invested into the risky project when incorporating income-rank comparisons $\left(a_{1}^{s}\right)$ must be larger than the optimal share without comparison considerations $\left(a_{1}^{*}\right)$, i.e. we observe $a_{1}^{s}>a_{1}^{*}$ (more risk taking). Analog follows that when the left-hand side of equation (7) is smaller than zero, $a_{1}^{s}<a_{1}^{*}$ must hold (i.e. subjects take less risk when incorporating rank-dependent comparisons). When the left-hand side of (7) is zero $a_{1}^{s}=a_{1}^{*}$ holds.

Considering $W>0>L$ and $f\left(a_{1}\right)$ being a density function, it is easy to see that the sign of the left-hand side of (7) is solely determined by $p_{G}$. When $p_{G}>\frac{1}{2}$ holds, the sign of the left-hand side of (7) will be positive, while in case of $p_{G}<\frac{1}{2}$ the sign will be negative. For $p_{G}=\frac{1}{2}$ the left-hand side of (7) will be zero. Intuitively, introducing rank-dependent comparison considerations will lead to more (less) risk taking in case more probability mass is on the good (bad) possible outcome of the risky project (i.e. more upside (downside) probability weight). Income-rank comparison will have no effect on risk taking in case of symmetric lotteries. Note that this holds even though we hold the expected return of the risky project constant. The first-order condition is sufficient as $C\left(a_{1}\right)$ is convex and as we assume that $a_{2}$ is uniformly distributed (i.e. $f\left(a_{1}\right)$ in $(7)$ is a constant).

Furthermore, we can consider the effect of a shift in probability weight between the bad and the good state on equilibrium risk taking. From (7) we see that ${ }^{13}$

$$
\frac{\partial a_{1}}{\partial p_{G}}=\frac{2 f\left(a_{1}\right) \times(W-L)+\left(\theta_{G}-1\right) \times u^{\prime}\left(a_{1} \theta_{G}+\left(1-a_{1}\right)\right)+u^{\prime}\left(1-a_{1}\right)}{C^{\prime \prime}\left(a_{1}\right)}>0,
$$

again relying on $C\left(a_{1}\right)$ being convex, $W>0>L$ and $f\left(a_{1}\right)$ being a constant. Equation (8) shows that income-rank comparison considerations lead to an equilibrium share invested into the risky investment that is increasing in $p_{G}$. Consequently, comparing lotteries with more upside (downside) probability weight, the equilibrium risk taking is higher for increasing upside probability weight (increasing in $p_{G}$ ) and lower for decreasing downside probability weight (decreasing in $\left(1-p_{G}\right)$ ). Put differently, the absolute effect of income-rank compar-

\footnotetext{
${ }^{13}$ Note that $C^{\prime}\left(a_{1}\right)$ depends directly on $p_{G}$ (see equation (11) in Appendix B.1).
} 
isons on risk taking is increasing for more asymmetrically allocated probability weight to the upside or to the downside.

\subsection{Experimental design}

The main part of the experiment consists of two treatments that are implemented in a between-subjects design. In each treatment subjects receive an endowment of 175 experimental currency units (ECU) that they allocate between a risky project (i.e. a lottery) and a risk-free project. ECUs invested into the risk-free project will be paid to subjects one-to-one while the return of the lottery depends on the outcome of independent dice rolls at the end of the experiment. A lottery pays a return $\theta_{G}>1$ with some probability $p_{G}$ while with a probability of $\left(1-p_{G}\right)$ the lottery pays nothing. ${ }^{14}$

Before the experiment starts subjects participate in a quiz in which each subject has to answer questions to ensure a good understanding of the experiment. ${ }^{15}$ Subjects play 9 independent rounds. In each round subjects receive a new endowment and face a new lottery that exhibits different probabilities $p_{G}$ and $\left(1-p_{G}\right)$ and different payoffs but an identical expected payoff of $p_{G} \times \theta_{G}$ (Table 1 shows all lotteries). ${ }^{16}$ The risk-free project remains unchanged over all rounds.

The computer randomly selects exactly one of the 9 rounds for payment. ${ }^{17}$ At the end of the experiment the lottery of the selected round appears on the screen of the participant. The experimenter enters the room and rolls dice clearly visible for the subject using a dice cup. ${ }^{18}$ The experimenter enters the results of the dice rolls into the computer and payoffs

\footnotetext{
${ }^{14}$ In the following we refer to $p_{G}$ as upside probability and to $1-p_{G}$ as downside probability.

${ }^{15}$ More precisely, subjects observe an investment decision and have to answer various questions about implications of the payoff given certain realizations of the lottery. At the beginning of the quiz subjects are asked to enter a number between 0 and 175 without knowing for what reason. This stated number determines the investment decision for the example that is used during the quiz. This twist allows us to present an example without introducing a default investment decision of the experimenter that could possibly influence the subsequent decisions of subjects during the main part of the experiment.

${ }^{16}$ Lotteries of different probabilities $p_{G}$ and $\left(1-p_{G}\right)$ ensure that each subject faces lotteries with more upside and lotteries with more downside probability weight.

${ }^{17}$ In principle, participants might perceive the 9 independent rounds as one compounded lottery even though at the end of the experiment exactly one round is randomly drawn and payoff relevant. If so, this would introduce an effect of earlier rounds on later rounds. However, such a behavior seems unlikely to be at work. First, in the instructions subjects are explicitly told to consider each round as independent from the earlier rounds. Second, usually narrow bracketing is a common behavior of individuals, and thus, we should expect that subjects treat the lotteries in different rounds as independent lotteries (for instance, see Rabin and Weizsäcker 2009). Finally, to control for a possible effect we implement a group of people that see the 9 independent rounds in a different sequence. As subjects only learn about lotteries of a round once a round starts a different sequence of rounds leaves participants with a different history of information at the beginning of each round. However, as we do not observe a significant difference in behavior between the two groups we conclude that participants indeed treat rounds as independent situations.

${ }^{18}$ We implemented physical dice rolls as this is a generally accepted, trustworthy mechanism to implement
} 
are accordingly calculated by the computer. ${ }^{19}$

Treatment Alone In the baseline treatment Alone each session consists of one subject so that each subject is alone in the room during the experiment. Nothing in the instructions indicates that other participants take part in the experiment. Subjects are invited with a time-lag to ensure that they never meet and that they are alone in the laboratory. During the experiment subjects observe the lottery for the current decision on a screen that is placed next to them but in the middle of the room. Subjects enter their decisions into a "private" screen in front of them. ${ }^{20}$

Treatment Social In treatment Social two subjects participate in each session and participants are aware of the other participant. ${ }^{21}$ In the laboratory room subjects sit in cubicles to ensure privacy. Importantly, both subjects know that in each round they invest into the same lottery as the other subject and that the final realization of the lottery at the end of the experiment is the same for both subjects. Subjects observe this "social" lottery on a single screen placed in the middle of the room. All decisions of subjects are entered into fields on their private screen in front of them. Before the experiment starts, subjects learn that one participant will be passive while the other will actively invest. It is commonly known that for the passive participant the computer randomly draws an investment share $a_{2}$ for the investment into the risky lottery from an unknown distribution. The computer draws $a_{2}$ anew and independently for each round and displays the current randomly drawn $a_{2}$ on the private screen of the passive subject only. The other participant decides actively on her investment share $a_{1}$, i.e. how much to invest into the risky lottery. While the active subject is aware of the passivity of the other subject the active subject never observes the passive subject's investments share $a_{2} \cdot{ }^{22}$ Analog, also the passive subject never observes the active participant's decision $a_{1}$.

The design feature of assigning one subject to be passive is important to rule out strategic interaction, but also costly due to many incentivized passive subjects to generate observa-

randomness. We intended to avoid the possibility that subjects doubt the fair randomness implementation of a computer (basically a "black box"). Note that dependent on the lottery the experimenter rolls one die or two dice. In case of two dice the experimenter rolls the dice one after the other.

${ }^{19}$ Note that the experimenter does not observe the investment decision of the subject when the dice roll results are entered into the computer, and thus, the experimenter does not learn the experimental income of the subjects.

${ }^{20}$ See Figure A.1 in Appendix A for an illustration of the setup.

${ }^{21}$ Note that subjects had to wait in front of the laboratory rooms (only for treatment Social). However, in most cases subjects sat separated by several chairs between them and we observed very little to no interaction between subjects.

${ }^{22}$ For more details see the instructions presented in Appendix C. 
tions. To make use of passive subjects we introduce a simple measure of subjective well-being in all treatments that we can later apply to test the effect of income-rank comparisons along this dimension. After each investment decision (or random draw in case of passive subjects) each participant is asked for her satisfaction with respect to the current lottery on a scale of 0 to 10 . To test the effect of income-rank comparisons using measured satisfaction we need a baseline treatment analog to treatment Alone.

Treatment Alone Passive This treatment is identical to treament Alone but that the single subject of each session is assigend to be passive meaning that the computer randomly draws $a$ from some distribution identical to the case explained above.

\subsection{Experimental procedures}

The experiment was programmed and conducted using the experiment software z-Tree (Fischbacher 2007) and run at the Max Planck Laboratory for Experimental Research in Social Science (econlab) in Munich. The participating subjects are enrolled at the Technical University of Munich and the University of Munich, and recruited from all different fields of study using ORSEE (Greiner 2004); for summary statistics and an overview of the treatments see tables A.1, A.2, and A.3 in Appendix A. After having completed the main experiment, subjects answer a set of post-experimental questions on individual characteristics and attitudes. At this point, we also conducted a set of incentivized post-experimental tasks including tests to assess risk aversion (à la Holt and Laury 2002, and a general risk-question, Dohmen et al. 2011). During the incentivized post-experimental tasks participants earned on average 1.2 Euros on top of the earnings from the main part of the experiment. Overall, participants earned on average 14.8 Euros including a show-up fee of 6 Euros and a session approximately lasted for 45 minutes.

\subsection{Predictions}

Pairwise comparisons between treatments allow us to investigate whether income-rank comparison considerations affect risk taking. While subjects face identical investment decisions in all treatments, in treatment Alone the investment decision affects only the personal income while in treatment Social the investment decision will also determine the relative performance (rank) compared to another participant in the laboratory. Thus, we can test the effect of income-rank-dependent utility analyzing the investment choice $a_{1}$ : Assuming that subjects care about their rank relative to another participant they adjust the share invested into the 


\begin{tabular}{|c|c|c|c|c|c|c|}
\hline \multirow{2}{*}{$\begin{array}{l}\text { Lotteries } \\
\quad n\end{array}$} & \multicolumn{2}{|c|}{ Probabilities } & \multicolumn{2}{|c|}{$\begin{array}{c}\text { Return } \\
\text { (multipliers) }\end{array}$} & \multirow{2}{*}{$\begin{array}{l}\text { Exp. Return } \\
\text { (multipliers) } \\
\frac{\theta_{G}}{a_{l} \times 175} \times p_{G}\end{array}$} & \multirow[t]{2}{*}{$\begin{array}{l}\text { Std. } \\
\text { Dev. }\end{array}$} \\
\hline & $\begin{array}{l}\text { Good state } \\
p_{G}\end{array}$ & $\begin{array}{l}\text { Bad state } \\
\left(1-p_{G}\right)\end{array}$ & $\begin{array}{c}\text { Good state } \\
\frac{\theta_{G}}{a_{l} \times 175} \\
\end{array}$ & $\begin{array}{c}\text { Bad state } \\
\theta_{B}\end{array}$ & & \\
\hline \multicolumn{7}{|l|}{ more } \\
\hline \multirow{2}{*}{\multicolumn{7}{|c|}{$\begin{array}{l}\text { downside } \\
\text { prob. weight }\end{array}$}} \\
\hline & & & & & & \\
\hline$L_{1}$ & $33 \%$ & $67 \%$ & 3.75 & 0 & 1.25 & 1.77 \\
\hline$L_{3}$ & $17 \%$ & $83 \%$ & 7.5 & 0 & 1.25 & 2.90 \\
\hline$L_{5}$ & $8 \%$ & $92 \%$ & 15 & 0 & 1.25 & 4.15 \\
\hline$L_{7}$ & $6 \%$ & $94 \%$ & 22.5 & 0 & 1.25 & 5.15 \\
\hline \multicolumn{7}{|l|}{ more } \\
\hline \multirow{2}{*}{\multicolumn{7}{|c|}{$\begin{array}{c}\text { upside } \\
\text { prob. weight }\end{array}$}} \\
\hline & & & & & & \\
\hline$L_{2}$ & $67 \%$ & $33 \%$ & 1.88 & 0 & 1.25 & 0.56 \\
\hline$L_{4}$ & $83 \%$ & $17 \%$ & 1.5 & 0 & 1.25 & 0.88 \\
\hline$L_{6}$ & $92 \%$ & $8 \%$ & 1.36 & 0 & 1.25 & 0.38 \\
\hline$L_{8}$ & $94 \%$ & $6 \%$ & 1.32 & 0 & 1.25 & 0.30 \\
\hline \multicolumn{7}{|l|}{ Symmetric } \\
\hline$L_{9}$ & $50 \%$ & $50 \%$ & 2.5 & 0 & 1.25 & 1.25 \\
\hline
\end{tabular}

Note: Each subject plays all lotteries and participates in one treatment only (between-subjects design). Returns of lotteries are stated as the multiplier for invested experimental currency units (ECUs). All probabilities are explained to subjects in terms of dice roll results, and thus, all probabilities are presented to subjects in an intuitive way. For example, consider Lottery $1\left(L_{1}\right)$ : in case the experimenter rolls a 6 using a regular die (i.e. out of $1, \ldots, 6$ ) the subject's invested ECUs will be multiplied by 3.75 , converted to Euros and paid to the subject at the end of the experiment. When the outcome is 5 or below the subject won't receive any money from the risky project (the invested ECUs are multiplied by zero). While we focus in our analysis on lotteries with more upside or downside probability weight according to our theoretical predicitions, we also implement one symmetric lottery $\left(L_{9}\right)$ that we can use for a plausibility check.

\section{Table 1: Lotteries}


risky lottery, $a_{1}$, when we compare situations where investment decisions have implications for the relative income position (rank) (in treatment Social) to situations where investment decisions have solely implications for the personal income (in treatment Alone):

Prediction 1 Comparing treatment Social to treatment Alone,

(i) for lotteries with more downside than upside probability mass $\left(p_{G}<\frac{1}{2}\right)$ subjects invest a lower share $a_{1}$ into the risky lottery (take less risk);

(ii) for lotteries with more upside than downside probability mass $\left(p_{G}>\frac{1}{2}\right.$ ) subjects invest a higher share $a_{1}$ into the risky lottery (take more risk).

Prediction 1 emanates from equation (7) of Section 2.1. Intuitively, the probability to be ahead of the other participant increases when subjects adjust their investment (relative to the situations without comparison considerations) so that the income is higher in the state that most probably materializes. ${ }^{23}$ We test Prediction 1 against the alternative hypothesis that individuals do not experience comparison concerns, and thus, that investment is similar in all treatments.

We can further analyze implications of income-rank comparison considerations for risk taking by considering the treatment difference between Social and Alone for lotteries with more or less asymmetrically allocated probability mass:

Prediction 2 Comparing treatment Social to treatment Alone, (i) for lotteries with more downside than upside probability mass subjects' investment into the risky lottery $a_{1}$ (risk taking) is decreasing in the downside probability mass $\left(1-p_{G}\right)$;

(ii) for lotteries with more upside than downside probability mass subjects' investment into the risky lottery $a_{1}$ (risk taking) is increasing in the upside probability mass $p_{G}$.

Prediction 2 follows from equation (8) of Section 2.1 and intuitively states that the absolute effect of income-rank comparisons on risk taking is larger when probability weights of a lottery are more asymmetrically allocated to either the downside or the upside. To test Prediction 2 we will exploit variation in the lotteries that subjects face and analyze the treatment difference of $a_{1}$ not only for lotteries with asymmetrically allocated probability mass but also for more or less asymmetrically allocated probability mass.

Focusing on passive subjects and measured satisfaction we can derive further testable predictions in line with Section 2.1. Passive subjects cannot adjust their investment, and thus, we can implement identical investment shares $a_{2}$ for both treatments Social and Alone

\footnotetext{
${ }^{23}$ More precisely, subjects tradeoff an expected utility gain (loss) from being ahead (behind) in rank with costs of deviating from their investment choice that would be optimal abstracting from comparison considerations (see Section 2.1).
} 
Passive. ${ }^{24}$ Thus, for passive subjects, comparing situations in which lotteries have implications for the rank in income (in treatment Social) to situation where lotteries have solely implications for the personal income (in treatment Alone Passive) participants should be less (more) satisfied when they are more likely to be behind (ahead) in expected income. To assess whether one is more likely to be ahead or behind, first, subjects need to form expectations about a plausible probability distribution of active subjects' investment choices $a_{1}$. Intuitively, such plausible expectations should incorporate that active subjects take less (more) risk in situations of more risky (less risky) lotteries. ${ }^{25}$ From this intuition, it follows that passive subjects should expect to be more likely to be behind in income-rank when lotteries have more upside probability weight and their randomly drawn investment share $a_{2}$ is very low or when lotteries have more downside probability weight and their investment share $a_{2}$ is very high. ${ }^{26}$ Thus, in such situations passive subjects should be less satisfied in treatment Social compared to treatment Alone Passive.

Prediction 3 Comparing treatment Social to treatment Alone Passive, passive subjects are less satisfied

(i) in situations of lotteries with more upside than downside probability mass and low $a_{2}$, and

(ii) in situations of lotteries with more downside than upside probability mass and high $a_{2}$.

To test Prediction 3 we implement groups of passive subjects with high and low randomly drawn $a_{2} \cdot{ }^{27}$ Furthermore, we ensure that randomly drawn investment shares $a_{2}$ of each group are identical between treatments Social and Alone Passive to perfectly control for any effect

\footnotetext{
${ }^{24}$ Recall, that $a_{2}\left(a_{1}\right)$ represents the share of risky investment for passive (active) subjects.

${ }^{25}$ This reasoning assumes that passive subjects anticipate that active subjects behave on average risk averse even for small stakes, a common behavior among individuals as a large body of experimental literature shows. Also note that the empirical distribution of investment decisions in this study also clearly shows that subjects behave risk averse in their investment decisions, and thus, passive subjects are correct when expecting risk averse behavior of active subjects.

${ }^{26}$ Again, this follows from Section 2.1. Also note that lotteries with more probability mass on the downside exhibit by construction higher standard deviations (are more risky) than lotteries with more probability mass on the upside (see Table 1).

${ }^{27}$ We implement two groups of passive subjects: a "high-risk" group that receives high risk shares and a "low-risk" group that receives low risk shares. In a first step, we recorded the empirical distribution of the first 10 active subjects in treatment Alone. Second, each group of passive subjects receives random draws from a different part of this recorded empirical distribution. The "high-risk" group receives random draws from the right part outside the $95 \%$ confidence interval of the empirical distribution of risk shares (i.e. relatively high $a_{2}$ ). The "low-risk" group receives random draws from the left part outside the $95 \%$ confidence interval of the empirical distribution of risk shares (i.e. relatively low $a_{2}$ ). Note that all risk-shares are determined (drawn) exactly once for each group and each portfolio choice problem, and thus, risk shares for each group of passive subjects are identical in both treatments, Social and Alone Passive.
} 
of $a_{2}$ on satisfaction that is unrelated to comparison considerations. ${ }^{28,29}$

\section{Results}

In a nutshell, we find that income comparisons lead to less risk taking in case of lotteries with more downside probability weight. For lotteries with more upside probability weight we find no significant effect. Furthermore, the characteristics of the reference individual are crucial for the effect of income comparisons on risk taking. Effects are stronger when the deciding (active) subject and the reference (passive) subject exhibit the same sex, and thus, when subjects are more similar.

Before we continue with the main analysis it is important to note that investment choices and satisfaction are sensitive to different portfolio choice situations. For instance, subjects invest a higher share of their endowment into the risky lottery (i.e. higher risk share $a_{1}$ ) when lotteries are less risky. Figure A.2 in Appendix A shows that subjects invest on average 59.0 percent of their endowment into the risky lottery when lotteries have a below median standard deviation compared to on average only 33.9 percent in case of an above median standard deviation lotteries. ${ }^{30}$ A negative correlation coefficient of -0.38 between the standard deviation of lotteries and the risk share $a_{1}$ confirms this result. When we consider measured risk aversion we find a negative relationship between being more risk averse and higher risk shares $a_{1}$ with a correlation coefficient of -0.20 , and thus, more risk averse subjects invest indeed less into the risky lottery choice just as one would expect. ${ }^{31}$

\footnotetext{
${ }^{28}$ Note that analog to Prediction 3, one might suspect that passive subjects should be more satisfied when being more likely to be ahead in rank when comparing treatment Social to treatment Alone. One might argue that this is the case in situations of lotteries with more upside probability weight and very high $a_{2}$ and in situations of lotteries with more downside probability weight and very low randomly drawn $a_{2}$. However, the case of being ahead is generally less clear because active subjects should react strategically to the comparison situations in treatment Social (in line with Section 2.1). Consequently, the uncertainty of being ahead in income in such situations is larger compared to being behind in income (as stated in Prediction 3) because active subjects will adjust their investment decision $a_{1}$ into the unfavorable direction for passive subjects.

${ }^{29}$ Note that it is not precisely clear how high (low) the randomly drawn investment share $a_{2}$ must be to observe Prediction 3. In principle, this depends on the expectations of passive subjects: subjects should be more (less) satisfied in treatment Social compared to treatment Alone Passive whenever they expect $a_{2}>a_{1}$ $\left(a_{2}<a_{1}\right)$, meaning a higher (lower) risky investment than the active subject in situations of lotteries with more upside probability weight. For lotteries more downside probability weight passive subjects should be more (less) satisfied in treatment Social whenever they expect $a_{2}<a_{1}\left(a_{2}>a_{1}\right)$.

${ }^{30}$ Note that by construction all lotteries with an above (below) median standard deviation are lotteries with more downside (upside) probability weight (see Table 1). However, here we focus on risk defined as variation (std. dev.) rather than on the asymmetric allocation of probability mass for the sake of this argument.

${ }^{31}$ We use a risk aversion measure à la Holt and Laury (2002) that essentially applies a multiple price list (MPL) of binary choices between lotteries. Note that this risk aversion measure is considerably less incentivized compared to the main part of the experiment. Thus, the consistent results support the general notion that the risk aversion measure à la Holt and Laury works well in the pecuniary dimension even when
} 
Finally, when we eyeball recorded satisfaction of passive subjects we observe that subjects report satisfaction in a sensible way. In case of an above median standard deviation lotteries (i.e. higher risk) passive subjects for which the computer draws a high (low) risk share are generally less (more) satisfied (see the left graph in Figure A.3, Appendix A). In case of a below median standard deviation (i.e. lower risk) lotteries passive subjects are more (less) satisfied if they receive a high (low) risk share (see the right graph in Figure A.3, Appendix A). ${ }^{32}$

\subsection{Individual risk taking}

To investigate the effect of social comparisons on risk taking we consider the change in investment (risk share) comparing treatment Alone and treatment Social. For a first test of Prediction 1 we separately compare risk taking behavior for lotteries with more downside or more upside probability mass between treatments Alone and Social. ${ }^{33}$ Our starting point is a first glance at simple averages. Figure (1) shows for more downside probability weighted lotteries a lower average risk share of 0.30 in treatment Social compared to an average risk share of 0.39 in treatment Alone in line with Prediction 1. Thus, in case of lotteries with more downside than upside probability mass subjects invest on average about $9 \%$ less of their endowment into the risky lottery when the otherwise identical lottery is payoff relevant for another subject. The treatment difference is significantly different when we conduct a Wilcoxon rank-sum test (p-value 0.050) or a two-sided t-test assuming unequal variances (pvalue 0.067$)$. Next, in case of lotteries with more upside than downside probability weight, we find a lower risk share of 0.57 in treatment Social compared to a risk share of 0.62 in treatment Alone. This difference is not significantly different using a Wilcoxon rank-sum test (p-value 0.250) or a two-sided t-test assuming unequal variances ( $p$-value 0.302). Hence, for lotteries with more upside probability mass we find the opposite sign as Prediction 1 suggests but this difference is statistically indistinguishable from zero while for lotteries with more downside probability mass we find a significant negative effect in line with Prediction $1 .^{34}$ Before we proceed with a regression analysis note that independent of the treatment subjects take significantly more risk in case of lotteries with more upside probability weight compared to lotteries with more downside probability mass, as we would expect. By construction, the

using comparable small stakes to incentivize subjects.

${ }^{32}$ Recall that we implement two groups of passive subjects: a "high-risk" group receiving high risk shares and a "low-risk" group receiving low risk shares (see more details in Section 2.4).

${ }^{33}$ Note that subjects also face one "symmetric" lottery (Lottery 9 in Table 1 has neither an probability overweight on the upside nor on the downside) that we can analyze for a plausibility check. In line with Section 2.1 we find no significant treatment effect in risk taking for Lottery 9 comparing treatment Social to Alone. This holds for simple means and for a regression analysis (not reported, available on request).

${ }^{34}$ Also see Table A.2 in Appendix A for descriptive statistics. 


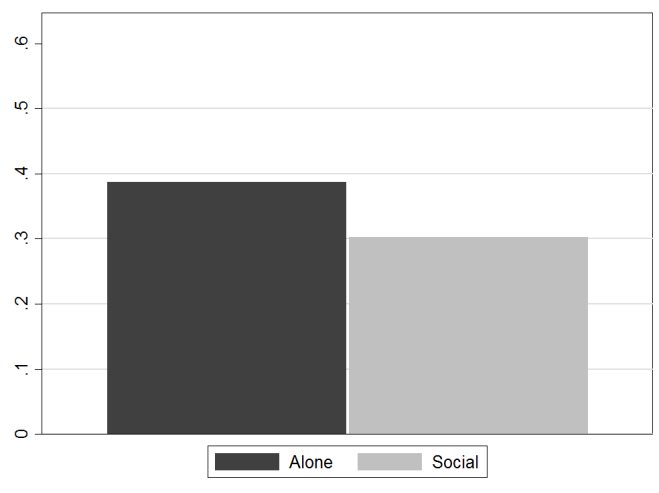

More downside prob. mass

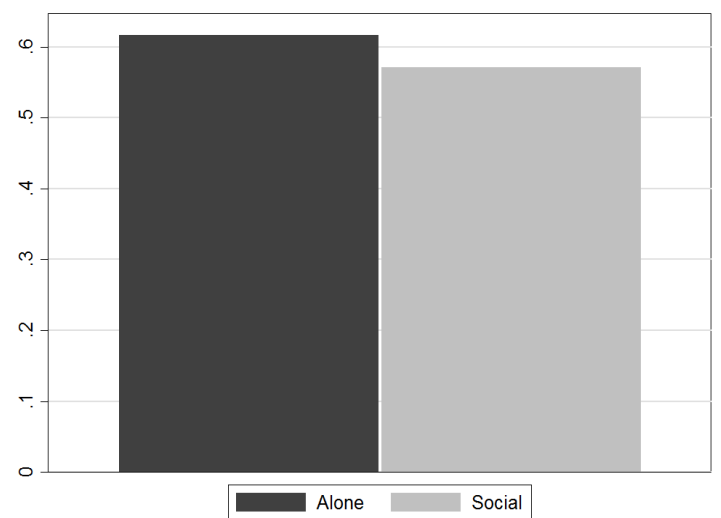

More upside prob. mass

\section{Figure 1: Average Share Invested Into Risky Lottery}

lotteries with more downside probability mass are mean-preserving spreads of the lotteries with more upside probability mass, and therefore, the lotteries with more upside probability mass second-order stochastically dominate the lotteries with more downside probability mass (also see Table 1 above). ${ }^{35,36}$

To further test Prediction 1 we run a random effects linear panel regression model on the observations of treatment Alone and of active subjects in treatment Social. ${ }^{37}$ The main

\footnotetext{
${ }^{35}$ Note that we construct lotteries with the goal to shift probability weight between the downside and the upside of the distribution (i.e., altering $p_{G}$ ). For a better comparability between lotteries, we hold the expected return constant over all lotteries by adding dispersion to the upside of the lotteries that have higher probability weights at the downside. While this procedure allows us to keep the simple binary structure of lotteries in our transformations, it effectively leads to two simultaneous changes w.r.t. to riskiness. First, risk changes by an intended change in the placement of risk between the upside and downside of a lottery. Second risk changes by a "pure risk increase or decrease" in the sense of Menezes et al. (1980) (more probability mass placed into the tails of the distribution leading to a higher variance). Menezes et al. (1980) show that risk averter and risk preferrers that exhibit prudence (i.e., the third derivative of a von Neumann-Morgenstern utility function is positive) dislike "pure downside risk", that is a placement of risk from the left to the right of a distribution, without altering neither the mean nor the variance.

${ }^{36}$ Note that the lotteries with more downside probability weight exhibit the properties of "long shots" (a high return with a low probability and positively skewed). Empirical evidence shows that bettors are attracted by "long shots" and are willing to forgo expected return for a higher positive skewness (Golec and Tamarkin 1998, Garrett and Sobel 1999). While such patterns in field data could be explained by risk preferring individuals (Quandt 1986), experimental evidence on the isolated effect of skewness on risk taking finds that individuals do indeed take more risk for more positively skewed lotteries (Grossman and Eckel 2015). Grossman and Eckel (2015) find that about 35\% of individuals take on higher levels of risk in case of positively skewed lotteries. This seems roughly consistent with the behavior of participant in this experiment, where we find that about $22 \%$ of participants invest more in riskier but positively skewed (i.e., more downside probability weight) lotteries than in less risky, negatively skewed (i.e., more upside probability weight) lotteries.

${ }^{37}$ We exclude subjects that inconsistently behaved in the test for risk aversion á la Holt and Laury (one
} 
specification is given by ${ }^{38}$

$$
\text { riskshare }_{i, n}=\beta_{0}+\beta_{1} \text { Social }+\beta_{2} I_{\text {upside }}+\beta_{3} \text { Social } \times I_{\text {upside }}+\beta X_{i, n}+\varepsilon_{i, n}
$$

The dependent variable riskshare $_{i, n}$ represents the share of endowment that subject $i$ invests into the risky lottery for lottery (portfolio choice) $n$ and takes values between 0 and 1. $I_{\text {upside }}$ is an indicator variable that takes a value of 1 if lottery $n$ has more upside than downside probability mass and a value of 0 in case of more downside than upside probability mass. Our variables of main interest are the treatment dummy Social that takes a value of 1 for observations from treatment Social, 0 otherwise and the interaction term Social $\times I_{\text {upside }}$. $X_{i, n}$ represents a vector of control variables. ${ }^{39}$ Coefficient $\beta_{1}$ of the interaction model (9) measures the treatment effect of comparison considerations (treatment Alone vs. treatment Social) on subjects' risk share in situations of lotteries with more downside probability weight $\left(I_{\text {upside }}=0\right)$. The coefficients $\beta_{1}$ and $\beta_{3}$ jointly measure the treatment effect in situations of lotteries with more upside probability weight $\left(I_{\text {upside }}=1\right)$.

In specification (1) of Table 2 we estimate model (9) without control variables. ${ }^{40}$ The coefficient of variable Social is -0.091 and significant at the $10 \%$ level (p-value 0.054 ). Thus, in line with Prediction 1, social comparison leads to significantly less risk taking in case of lotteries that have more downside than upside probability weight. More precisely, subjects invest 9.1 percentage points less of their endowment into the risky lottery. On the other hand, the joint effect of variables Social and Social $\times I_{\text {LeftS }}$ is -0.049 and not significantly different from zero (p-value 0.292) as an F-test shows. Hence, the treatment effect in situations of lotteries with more upside probability mass shows the opposite (negative) sign as predicted by Prediction 1 but is statistically indistinguishable from zero. Finally, the positive and highly significant coefficient of 0.231 ( $\mathrm{p}$-value 0.000 ) for variable $I_{\text {upside }}$ shows that independent of the treatment effect subjects generally take considerably more risk in situations of lotteries

subject in treatment Alone and 4 subjects in treatment Social). However, all results are robust to including all subjects.

${ }^{38}$ Results are robust to using a simple pooled OLS model with clustered standard errors at the subject level or a random effects tobit model that accounts for potential problems related to censoring.

${ }^{39} \mathrm{We}$ include as individual controls a measure of risk aversion à Holt and Laury, gender, age, an indicator variable whether the field of study is related to business or economics, an indicator variable whether subjects participated in laboratory experiments before, measures of patience and impulsiveness, and a measure whether subjects tend to be envious. We also include a fixed effect for each round of the experiment (point in time) and a control variable that controls for the sequence of the rounds (i.e. sequence of lotteries; more precisely, we implemented two groups that saw lotteries in two different randomized sequences; the group dummy is our control for the sequence of lotteries).

${ }^{40}$ Note that all individual control variables are self-reported after the main experiment, and thus, could be potentially endogenous. Therefore, it is comforting to see that our findings are robust even without including control variables. 


\begin{tabular}{|c|c|c|c|c|}
\hline & $\begin{array}{c}\text { All } \\
\text { asymmetric } \\
\text { lotteries } \\
(1) \\
\text { risk share }\end{array}$ & $\begin{array}{c}\text { All } \\
\text { asymmetric } \\
\text { lotteries } \\
(2) \\
\text { risk share }\end{array}$ & $\begin{array}{c}\text { More } \\
\text { asymmetric } \\
\text { lotteries } \\
(3) \\
\text { risk share }\end{array}$ & $\begin{array}{c}\text { Less } \\
\text { asymmetric } \\
\text { lotteries } \\
(4) \\
\text { risk share }\end{array}$ \\
\hline Social & $\begin{array}{l}-0.091^{*} \\
(0.047)\end{array}$ & $\begin{array}{c}-0.115^{* *} \\
(0.045)\end{array}$ & $\begin{array}{c}-0.150^{* * *} \\
(0.058)\end{array}$ & $\begin{array}{l}-0.080^{*} \\
(0.046)\end{array}$ \\
\hline$I_{\text {upside }}$ & $\begin{array}{c}0.231^{* * *} \\
(0.045)\end{array}$ & $\begin{array}{c}0.217^{* * *} \\
(0.044)\end{array}$ & $\begin{array}{c}0.331^{* * *} \\
(0.067)\end{array}$ & $\begin{array}{c}0.166^{* * *} \\
(0.042)\end{array}$ \\
\hline Social $\times I_{\text {upside }}$ & $\begin{array}{c}0.042 \\
(0.060)\end{array}$ & $\begin{array}{c}0.042 \\
(0.061)\end{array}$ & $\begin{array}{c}0.067 \\
(0.090)\end{array}$ & $\begin{array}{c}0.017 \\
(0.057)\end{array}$ \\
\hline risk aversion $i$ & & $\begin{array}{c}-0.033^{* * *} \\
(0.012)\end{array}$ & $\begin{array}{c}-0.039^{* * *} \\
(0.015)\end{array}$ & $\begin{array}{c}-0.027^{* * *} \\
(0.013)\end{array}$ \\
\hline Constant & $\begin{array}{c}0.384^{* * *} \\
(0.034)\end{array}$ & $\begin{array}{c}0.414^{* * *} \\
(0.115)\end{array}$ & $\begin{array}{c}0.545^{* * *} \\
(0.136) \\
\end{array}$ & $\begin{array}{l}0.246^{*} \\
(0.145)\end{array}$ \\
\hline $\begin{array}{l}\text { Individual } \\
\text { controls }\end{array}$ & No & Yes & Yes & Yes \\
\hline $\begin{array}{l}\text { Time and sequence } \\
\text { fixed effects }\end{array}$ & No & Yes & Yes & Yes \\
\hline$N$ & 672 & 672 & 336 & 336 \\
\hline Clusters & 84 & 84 & 84 & 84 \\
\hline
\end{tabular}

Note: Random effects panel regression. Dependent variable: share invested into risky lottery. Standard errors in parentheses, ${ }^{*} \mathrm{p}<0.10,{ }^{* *} \mathrm{p}<0.05,{ }^{* * *} \mathrm{p}<0.01$. Specifications (1) and (2) include all observations of asymmetric lotteries (i.e., lotteries with more upside or downside probability mass) from treatments Alone and Social. Specifications (3) includes the subsample of more asymmetric lotteries (see $\mathrm{L}_{5}, \mathrm{~L}_{6}, \mathrm{~L}_{7}, \mathrm{~L}_{8}$ in Table (1) of Appendix (A)). Specifications (4) includes the subsample of less asymmetric lotteries (see $\mathrm{L}_{1}$, $\mathrm{L}_{2}, \mathrm{~L}_{3}, \mathrm{~L}_{4}$ in Table (1) of Appendix (A)). "Individual controls" include gender, age, whether the field of study is business related, risk aversion, impulsivness and patience, enviousness, and a dummy whether subjects participted in laboratory expermints before. "Time and sequence fixed effects" include period fixed effects and a dummy for the sequence in which lotteries are shown.

Table 2: Income-rank dependent preferences: Regression results for risk-taking 
with more upside probability mass compared to situations of lotteries with more downside probability mass. This is as one would expect because of the generally higher standard deviations (risk) of lotteries with more downside probability weight. ${ }^{41}$ Specification (2) confirms these findings where we include individual-specific socioeconomic characteristics, variables from post-experimental tasks, and time and sequence-of-lotteries fixed effects. Note that the individual control risk aver sion $i$ has a coefficient of -0.033 that is significant at the $1 \%$ level (p-value 0.008), and thus, more risk-averse subjects generally invest significantly less into the risky lottery of a portfolio choice problem as one would suspect. ${ }^{42}$

Result 1 Comparison considerations affect risk taking: individuals invest less risky in situations of lotteries with more downside than upside probability mass. In situations of more upside than downside probability mass comparison considerations do not significantly affect risk taking behavior.

To shed some light on Prediction 2, whether more asymmetrically allocated probability mass affects risk-taking more (less), we estimate model (9) on subsamples of lotteries with more or less asymmetrically allocated probability mass. In specification (3) we consider only a subset of more asymmetric lotteries (lotteries $\mathrm{L}_{5}, \mathrm{~L}_{7}, \mathrm{~L}_{6}, \mathrm{~L}_{8}$ of Table 1). More asymmetric lotteries show a more significant and in absolute size larger treatment effect of -0.150 (p-value 0.009 ) in situations of lotteries with more downside probability mass in line with Prediction 2. In situations of lotteries with more upside probability mass the effect remains insignificant. ${ }^{43}$ In specification (4) we consider a subset of less asymmetric lotteries (lotteries $\mathrm{L}_{1}, \mathrm{~L}_{3}, \mathrm{~L}_{2}, \mathrm{~L}_{4}$ of Table 1) and find a less significant and in absolute size smaller effect of -0.0795 (p-value 0.086) for lotteries wiht more downside probability mass in line with Prediction 2. In case of lotteries with more upside probability mass the effect remains again statistically indistinguishable from zero. ${ }^{44}$ Thus, while we find evidence in line with Prediction 2 for lotteries with more downside probability mass, for lotteries with more upside probability mass we find no statistically significant effect, consistent with our findings above. ${ }^{45}$

\footnotetext{
${ }^{41}$ Recall that lotteries with more downside probability weight are mean preserving spreads of lotteries with more upside probability weight by construction.

${ }^{42}$ Note that we experimented with different measures of risk aversion. In our regressions we use a multiple price list measure à la Holt and Laury as this measure shows the highest explanatory power. Using the general risk-question of Dohmen et al. (2011) as a measure of risk aversion shows the correct sign in most specifications but is only weakly or not at all significant. Thus, our results imply that in the financial dimension an incentivized multiple price list measure seems to be a better measure to assess risk aversion.

${ }^{43}$ In specification (3) the sum of coefficients of variables Social and Social $\times I_{\text {upside }}$ is insignificant (p-value $0.34)$ using an F-test.

${ }^{44}$ In specification (4) the sum of coefficients of variables Social $_{i}$ and Social $_{i} \times I_{u p s i d e}$ is insignificant $(\mathrm{p}-$ value 0.245 ) using an F-test.

${ }^{45}$ Note, however, that we find no statistically significant difference between our subsamples of more and
} 
Result 2 The effect of comparison considerations on risk taking appears to be larger (smaller) in absolute terms for lotteries with more downside probability mass when probability mass is allocated even more asymmetrically. In case of lotteries with more upside than downside probability mass neither a more nor a less asymmetric allocation of the probability mass shows a significant effect.

A natural next step is to analyze factors that foster the effect of comparison considerations on risk taking. An influential idea first discussed by Festinger (1954) is that individuals compare themselves to more similar rather than to less similar individuals, and thus, we might expect stronger comparison effects for more similar subjects. ${ }^{46}$ During the experiment we intentionally provide a large degree of anonymity to limit potential noise from the interaction of individuals that might be related to subjective sympathy or other factors that are difficult to control for. Although subjects do not interact they enter the room in which the experiment takes place together (in treatment Social), and thereby, see the other participant of their session before taking a seat behind their private cubicle. While it is difficult to assess what subjects learn from this short visual impression of their reference subject, it seems plausible that subjects at least get to know the gender of the other participant. Thus, when we think of gender as one dimension in which subjects can be more or less similar we can expect that subjects grouped with another participant of the same gender (more similar subjects) experience a stronger comparison effect on risk taking than subjects grouped with another participant of a different gender (less similar subjects). Furthermore, we can also exploit our data to investigate a general gender effect. Many studies in the experimental literature find that risk taking exhibits a gender related component, and thus, social comparison related risk taking behavior might also differ along the gender dimension, independently of Festinger's similarity idea. ${ }^{47,48}$

In specifications (1) and (2) of Table 3 we estimate model (9) as above but focus only on subsamples of subjects that are grouped with another subject of the same gender in treatment Social. ${ }^{49}$ In specification (1) we focus on the treatment effect for female-female

less asymmetric lotteries in a formal test. We interact a dummy variable that takes the value of 1 for lotteries from the subsample of more asymmetric lotteries and zero for less asymmetric lotteries with the treatment dummy Social. We estimate this interaction model separately for more downside and more upside probability mass lotteries on observations from treatments Alone and Social. We cannot reject that the interaction term is equal to zero in neither specification.

${ }^{46}$ Festinger (1954) refers to situations when subjects compare their own ability to the ability of others while we are interested in an extension of his idea to income comparisons.

${ }^{47}$ Many studies in the experimental literature find that women take less risk than men do (e.g., see Charness and Gneezy 2012). However, some studies argue that gender differences are small and context specific (e.g., Schubert et al., 1999).

${ }^{48}$ We find that male subjects invest on averge $4.7 \%$ more of their endowment into the risky lottery compared to female subjects in our experiment. This difference, however, is insignificant.

${ }^{49}$ More precisely, in specification (1) we compare female subjects in treatment Alone to female-female pairs 


\begin{tabular}{|c|c|c|c|c|}
\hline & $\begin{array}{c}\text { Female } \\
\text { with } \\
\text { Female } \\
(1) \\
\text { risk share }\end{array}$ & $\begin{array}{c}\text { Male } \\
\text { with } \\
\text { Male } \\
(2) \\
\text { risk share }\end{array}$ & $\begin{array}{c}\text { Female } \\
(3) \\
\text { risk share }\end{array}$ & $\begin{array}{c}\text { Male } \\
(4) \\
\text { risk share }\end{array}$ \\
\hline Social & $\begin{array}{c}-0.191^{* * *} \\
(0.043)\end{array}$ & $\begin{array}{c}-0.133^{* *} \\
(0.066)\end{array}$ & $\begin{array}{c}-0.133^{* * *} \\
(0.050)\end{array}$ & $\begin{array}{l}-0.046 \\
(0.081)\end{array}$ \\
\hline$I_{\text {upside }}$ & $\begin{array}{c}0.186^{* * *} \\
(0.064)\end{array}$ & $\begin{array}{c}0.276^{* * *} \\
(0.063)\end{array}$ & $\begin{array}{c}0.186^{* * *} \\
(0.064)\end{array}$ & $\begin{array}{c}0.276^{* * *} \\
(0.063)\end{array}$ \\
\hline $\begin{array}{l}\text { Social } \\
\quad \times I_{\text {upside }}\end{array}$ & $\begin{array}{c}0.165^{* *} \\
(0.079)\end{array}$ & $\begin{array}{c}0.041 \\
(0.095)\end{array}$ & $\begin{array}{c}0.115 \\
(0.078)\end{array}$ & $\begin{array}{l}-0.033 \\
(0.094)\end{array}$ \\
\hline Constant & $\begin{array}{c}0.389^{* * *} \\
(0.035)\end{array}$ & $\begin{array}{c}0.379^{* * *} \\
(0.058)\end{array}$ & $\begin{array}{c}0.389^{* * *} \\
(0.035)\end{array}$ & $\begin{array}{c}0.379^{* * *} \\
(0.058)\end{array}$ \\
\hline $\begin{array}{l}\text { Individual } \\
\text { controls }\end{array}$ & No & No & No & No \\
\hline $\begin{array}{l}\text { Time and sequence } \\
\text { fixed effects }\end{array}$ & No & No & No & No \\
\hline$N$ & 280 & 272 & 344 & 328 \\
\hline Clusters & 35 & 34 & 43 & 41 \\
\hline
\end{tabular}

Note: Random effects panel regression model. Dependent variable: share invested into the risky lottery. Standard errors in parentheses, ${ }^{*} \mathrm{p}<0.10,{ }^{* *} \mathrm{p}<0.05,{ }^{* * *} \mathrm{p}<0.01$. Gender-specific subsamples. Specifiations (1) and (2) apply subsamples in which grouped subjects are of the same gender in treatment Social and of the corresponding same gender in treatment Alone (female-female compared to female and male-male compared to male). Specifications (3) and (4) focus simply on gender without considering the gender of the other (reference) subject in treatment Social.

Table 3: Subjects of the same gender 
pairs. We find that the coefficient of Social is larger in absolute terms $(-0.191)$ and more significant (p-value 0.000) compared to our results reported above. An F-test shows that the sum of the coefficients of Social and Social $\times I_{\text {upside }}$ is not significantly different from zero. Thus, focusing on female-female pairs provides similar but stronger results than the general specification estimated above with a significant negative effect in case of lotteries with more downside probability weight but no significant effect for lotteries with more upside probability weight. In specification (2) we focus on a subsample of male-male pairs. We find an in absolute terms slightly larger coefficient for Social than in the complete sample $(-0.133)$ that is significant at the $5 \%$ level (p-value 0.046). However, in situations of lotteries with more downside probability weight this negative effect is smaller in absolute terms compared to female-female pairs. For lotteries with more upside probability weight we also find in the male-male subsampel a statistical zero effect. ${ }^{50,51}$ Finally, in specifications (3) and (4) we plainly focus on the gender of the deciding subject without considering the gender of the reference subject. In specification (3), using a subsample of female subjects, we find a sizable negative effect for lotteries with more downside probability mass (coefficient of Social : -0.133) that is significant at the $1 \%$ level (p-value 0.008). In situations of lotteries with more upside probability mass we find no significant effect. ${ }^{52}$ Focusing on male subjects in specification (4) we find neither a significant effect for lotteries with more downside ( $\mathrm{p}$ value 0.575 ) nor more upside ( $\mathrm{p}$-value 0.28 ) probability mass. Thus, in line with the idea of Festinger (1954) we find larger estimated effects of comparison concerns on risk taking for more similar subjects compared to the full sample. Robust to our findings above, comparison considerations affect risk taking in situations of lotteries with more downside probability mass but not for lotteries with more upside probability mass. Finally, our results indicate that effects of comparisons on risk taking appear to be more pronounced for female than for male subjects although we cannot reject the hypothesis of no gender differences in a formal test. ${ }^{53}$

in treatment Social. Analog, in specification (2) we compare male subjects in treatment Alone to male-male pairs in treatment Social.

${ }^{50}$ In the male-male subsample the sum of the coefficients of Social and Social $* I_{\text {upside }}$ is indistinguishable from zero using an F-test (p-value 0.24).

${ }^{51}$ Note, that same-gender pairs show a significantly stronger treatment effect to social comparisons for lotteries with more downside probability mass. In a formal test we first create a dummy variable that takes a value of 1 for different-gender pairs and 0 for same-gender pairs. We interact this variable with the treatment dummy that takes a value of 1 for observations in treatment Social. This interaction model is separately estimated for lotteries with more downside and upside probability weight on observations from treatments Alone and Social. The estimate of the interaction term is significantly different from zero at the $5 \%$ level for lotteries with more downside probability weight. Results are reported in Table A.4 of Appendix A.

${ }^{52}$ An F-test for the sum of Social and Social $* I_{\text {upside }}$ shows again a statistical zero effect in situations of lotteries with more upside probability mass (p-value, 0.76) for the subsample of female subjects.

${ }^{53}$ We interact a dummy variable taking the value of 1 for male subjects and 0 for female subjects with a treatment dummy that takes a value of 1 for observations in treatment Social. We estimate this interaction 
Result 3 Comparison considerations affect risk taking more when the reference subject is of the same gender.

\subsection{Evidence from satisfaction}

We can make use of observations of passive subjects by investigating measured satisfaction. In a first step, we consider simple means to investigate Prediction 3. Figure 2 shows mean satisfaction of passive subjects in situations of lotteries with more downside and lotteries with more upside probability mass for low-risk and high-risk groups. ${ }^{54}$ Recall that in situations of lotteries with more upside probability mass and low risk share and in situations of lotteries with more downside probability mass and high risk share passive subjects are likely to be behind in rank compared to the active reference subject. Consequently, in these situations theory predicts passive subjects to be less satisfied in treatment Social compared to treatment Alone Passive. We find that subjects are indeed less satisfied for lotteries with more upside probability mass and low risk shares (see Figure 2, upper right corner), reporting by 1.70 points lower satisfaction in treatment Social compared to treatment Alone Passive. This difference is significant at the $5 \%$ level when we apply a non-parametric Wilcoxon rank-sum test (p-value 0.012 ) and significant at the $1 \%$ level for a two-sided t-test assuming unequal variances (p-value. 0.0002). In all other situations, including situations of lotteries with more downside probability mass and high risk shares (Figure 2, lower left corner) we do not find a significant difference in satisfaction between treatment Alone Passive and treatment Social. Thus, we find evidence in line with Prediction 3 in situations of lotteries with more upside probability mass and low risk shares but no significant effect in case of lotteries with more downside probability mass and high risk shares.

To elaborate further on these findings we run a random effects linear panel regression model on the observations of treatment Alone Passive and passive subjects of treatment Social. ${ }^{55}$ We estimate the following model:

$$
\text { satisfaction }_{i, n}=\beta_{0}+\beta_{1} \text { Social }+\beta_{2} I_{H i g h \_ \text {Risk }}+\beta_{3} \text { Social } \times I_{H i g h \_ \text {Risk }}+\varepsilon_{i, n}
$$

The dependent variable satisfaction $_{i, n}$ is reported satisfaction of passive subject $i$ facing

model separately for lotteries with more downside and upside probability mass on observations from treatments Alone and Social. We cannot reject that the coefficient for the interaction term is equal to zero in neither specification.

${ }^{54}$ Recall that we implement two groups: one that receives high and one that receives low risk shares. See Section 2.4 for more details.

${ }^{55}$ Results are robust to using a pooled OLS model with clustered standard errors on subject level. Since satisfaction is an ordinal concept we also apply a random effects ordered probit model and find that results are robust, in line with Ferrer-i-Carbonell and Frijters (2004). 


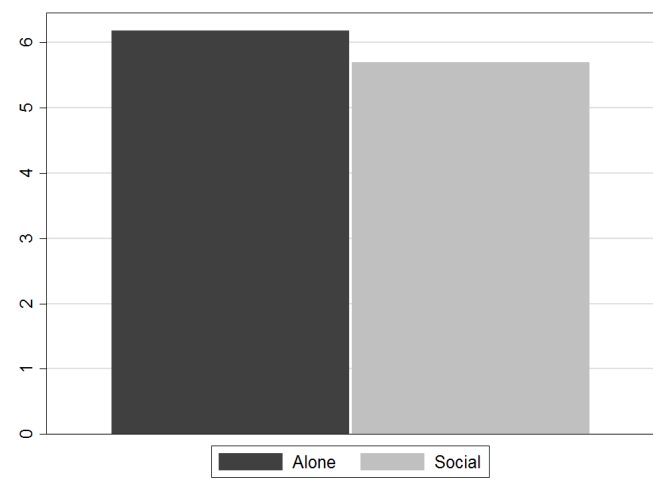

Downside prob. mass \& low risk

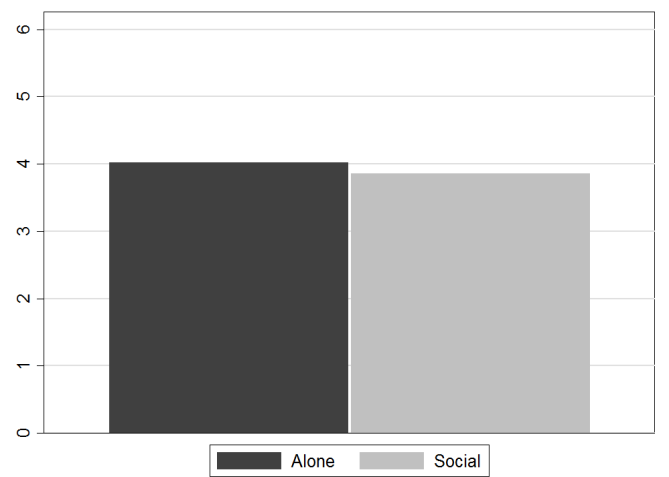

Downside prob. mass \& high risk

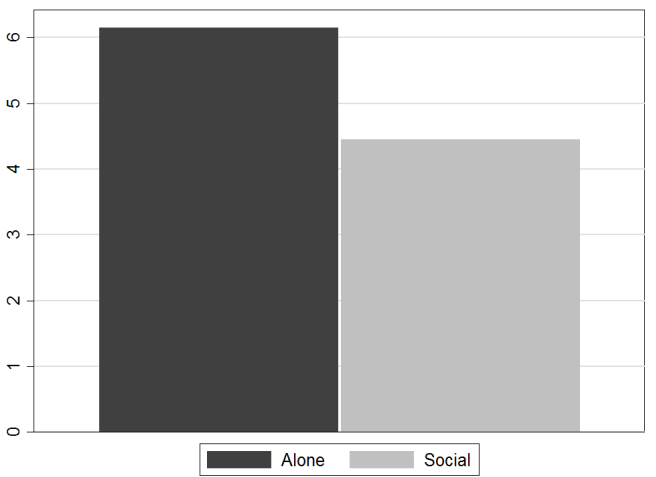

Upside prob. mass \& low risk

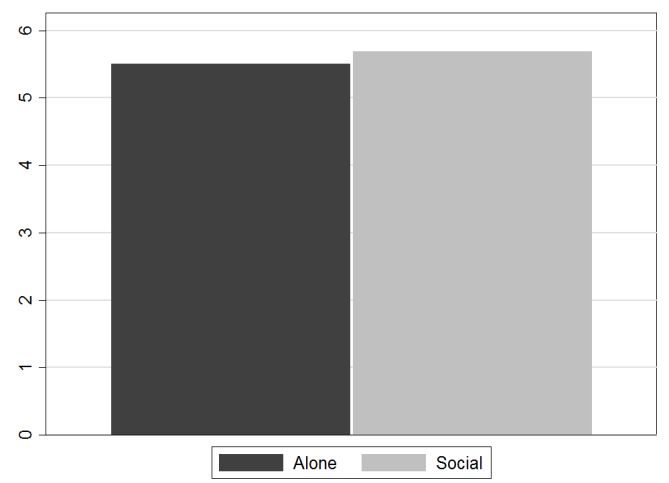

Upside prob. mass \& high risk

Figure 2: Average satisfaction of passive subjects in different situations 


\begin{tabular}{lcc}
\hline \hline & Upside & Downside \\
& probability mass & probability mass \\
lotteries & $(1)$ & lotteries \\
& satisfaction & satisfaction \\
\hline Social & $-1.702^{* * *}$ & -0.491 \\
& $(0.400)$ & $(0.467)$ \\
$I_{\text {High_Risk }}$ & -0.656 & $-2.163^{* * *}$ \\
Social $\times$ & $(0.553)$ & $(0.516)$ \\
$I_{\text {High_Risk }}$ & $1.889^{* *}$ & 0.320 \\
Constant & $(0.768)$ & $(0.848)$ \\
& $6.156^{* * *}$ & $6.188^{* * *}$ \\
Individual & $(0.228)$ & $(0.296)$ \\
controls & & No \\
Time and sequence & No & No \\
fixed effects & No & \\
\hline$N$ & & 63 \\
Clusters & 252 & \\
\hline \hline
\end{tabular}

Note: Random effects panel regression model. Dependent variable: satisfaction. Standard errors in parentheses, ${ }^{*} \mathrm{p}<0.10,{ }^{* *} \mathrm{p}<0.05,{ }^{* * *} \mathrm{p}<0.01$. Dependent variable: reported satisfaction of passive subjects. The sample includes observations from treatment Alone Passive and passive subjects from treatment Social. Specification (1) incorporates the subsample of lotteries with more upside probability mass (lotteries $\mathrm{L}_{2}, \mathrm{~L}_{4}$, $\mathrm{L}_{6}, \mathrm{~L}_{8}$ of Table 1). Specification (2) incorporates the subsample of lotteries with more downside probability mass (lotteries $\mathrm{L}_{1}, \mathrm{~L}_{3}, \mathrm{~L}_{5}, \mathrm{~L}_{7}$ of Table 1 ).

Table 4: Satisfaction of passive subjects with high and low risk shares.

lottery $n . I_{\text {High_Risk }}$ is an indicator variable that takes a value of 1 for subjects receiving a high risk share from the computer (high-risk group) and 0 for subjects receiving a low risk share (low-risk group). Our variables of main interest are variables Social, a treatment dummy that takes a value of 1 for observations of treatment Social, and the interaction term Social $\times I_{\text {High_Risk. }}$. Coefficient $\beta_{1}$ measures the treatment effect on satisfaction for subjects receiving low risk shares $\left(I_{H i g h \_R i s k}=0\right)$ while the sum of $\beta_{1}$ and $\beta_{3}$ measures the treatment effect for high risk share subjects $\left(I_{H_{i g h} \text { Risk }}=1\right)$.

In specification (1) of Table 4 we estimate model (10) on the set of lotteries with more upside probability mass (lotteries $\mathrm{L}_{2}, \mathrm{~L}_{4}, \mathrm{~L}_{6}, \mathrm{~L}_{8}$ of Table 1 ). The coefficient of Social is -1.702 and significant at the $1 \%$ level (p-value 0.000). Thus, subjects are significantly less satisfied in treatment Social compared to Alone Passive when they receive a low risk share 
and face more probability mass on the upside (when they are more likely to be behind). In situations of high risk shares we find a positive but insignificant treatment effect. ${ }^{56}$

In Specification (2) we estimte the identical model on the set of lotteries with more downside probability mass (lotteries $\mathrm{L}_{1}, \mathrm{~L}_{3}, \mathrm{~L}_{5}, \mathrm{~L}_{7}$ of Table 1 ). We find neither a significant treatment effect for high nor for low risk shares. ${ }^{57}$ The negative and significant coefficient of $I_{\text {High_Risk }}(-2.163$, p-value 0.000$)$ shows a strong negative reaction in satisfaction comparing high to low risk shares independent of the treatments Social and Alone. This strong effect is only present in situations of lotteries with more downside probability mass as these lotteries exhibit by construction a considerably higher riskiness (standard deviation) compared to lotteries with more upside probability mass in our experiment (also see Table 1).

Result 4 Comparison considerations adversely affect satisfaction of subjects when subjects are likely to be behind in income compared to another subject in situations of lotteries with more upside probability mass.

It is interesting that we only find an effect for being behind in expected income-rank in situations of lotteries with more upside probability mass. One possible explanation for this result is that passive subjects might find it more difficult to assess the behavior of active subjects in case of lotteries with more downside probability mass compared to lotteries with more upside probability mass. The latter lotteries exhibit by construction comparably little risk, and thus, it might appear straightforward to predict that most active participants invest a larger share of their endowment into the risky lottery. Thus, "low-risk group" passive subjects might find it straightforward to predict to be behind in expected rank. On the other hand, lotteries with more downside probability mass are considerably more risky by construction but offer consequently more extreme returns (a "long shot"). Passive subjects might anticipate that the extreme (low probability) returns are potentially attractive for some active participants, and thus, passive subjects might find it less straightforward to predict the behavior of active subjects. ${ }^{58}$ Consequently, passive subjects might experience a higher strategic uncertainty for the lotteries with more downside probability mass than for lotteries with more upside probability mass that could explain the weaker results. ${ }^{59}$

\footnotetext{
${ }^{56}$ The sum of the coefficients of Social and Social $\times I_{\text {High }}$ Risk is positive (0.187) and not significantly different from zero using an F-test (p-value 0.775)

${ }^{57}$ Neither the coefficient of Social (-0.491, p-value 0.294) nor the sum of coefficients of Social and Social $\times I_{\text {High_Risk }}(-0.171$, p-value 0.809$)$ are statistically distinguishable from zero.

${ }^{58}$ Note that the low probability, high return of some of the lotteries with more downside probability mass can be considered to be substantial for a student participating in a laboratory experiment (in the best case more than 100 EUR).

${ }^{59}$ For instance, Kahneman and Tversky (1979) suggest that individuals might overweight low probabilities. Camerer and Kunreuther (1989) discuss that individuals face problems to handle low probabilities and either
} 


\subsection{Higher risk for the relative income position: uncorrelated lot- tery returns}

In Section 3.1 we find that comparison concerns induce less risk taking for lotteries with more downside probability weight while we find no statistically significant effect for lotteries with more upside probability weight. What explains this asymmetric result? One possible candidate for an explanation is that subjects do not care so much about their income rank but rather about the distance in income relative to others for their risk taking decisions, as first theoretically discussed by Konrad and Lommerud (1993). To see why this might explain the asymmetric result, first consider lotteries with more upside and lotteries with more downside probability mass (see Table 1). By construction, lotteries with more downside probability weight exhibit higher risk (i.e. higher standard deviations) than lotteries with more upside probability weight. Thus, one could also read the results of Section 3.1 as follows: Comparison considerations lead to less risk taking in situations of higher risk. This interpretation would be in line with Konrad and Lommerud (1993) who show that comparison considerations lead to less risk taking when individuals are relatively more risk averse with regard to their relative income position than with regard to their pure consumption. ${ }^{60}$

To investigate whether the individuals' preferences for the distance in income can explain our results we run a control treatment in which we increase the risk for the relative income position while, at the same time, we keep the risk for the personal income unchanged (treatment "Social Uncorr"). ${ }^{61}$ The idea of this treatment is inspired by Konrad and Lommerud (1993) who show that the correlation structure of risk, e.g. correlated or uncorrelated income risks, can matter. Social Uncorr is identical to treatment Social except for that the returns of the risky lottery are uncorrelated for subjects. More precisely, while in treatment Social the identical dice rolls determine the return of the risky lottery for both subjects, in treatment Social Uncorr for each subject dice are independently rolled, and thus, the return of the risky lottery is independently determined. ${ }^{62}$ Thus, while in treatment Social

dismiss or overestimate these. Furthermore, evidence shows that some individuals are attracted by the "long shot" properties that are common to the lotteries with more downside probability weight (also see footnote 36 above). Summing up, assessing how other subjects respond to low probability events with rather "extreme" returns (and positively skewed probability distributions) might be particularly difficult for subjects.

${ }^{60}$ Note that this holds for the case of non-systematic (uncorrelated) risk in Konrad and Lommerud's (1993) theoretical study. In our main treatment the lottery payoffs are perfectly correlated for subjects. However, different to the assumption of a symmetric investment decision in Konrad and Lommerud (1993), risk shares for the reference (passive) subjects are randomly drawn in our study. This introduces additional risk for the relative income position of active subjects and effectively leads to a situation comparable to "non-systematic risk" in Konrad and Lommerud (1993).

${ }^{61}$ We run additional 44 sessions with 88 participants. Also see Table A.1 in Appendix A.

${ }^{62}$ Subjects learn about the procedure (one-for-all or independent dice rolls) from the instructions before the experiment starts (e.g., see Appendix C for the instructions of treatment Social). 
both subjects of a session receive either a positive or a zero payoff from the risky lottery, in treatment Social Uncorr subjects can also end up with a positive (zero) payoff from the risky lottery while the other participant receives a zero (positive) payoff. Consequently, subjects can be relatively further ahead or behind in income in treatment Social Uncorr than in Social, leading to higher risk in the social dimension.

When the distance in incomes of subjects causes our asymmetric results of Section 3.1 we would expect that subjects respond to the higher risk in the social dimension accordingly. Tjhus, we would expect that subjects reduce risk taking comparing treatment Social Uncorr to treatment Social (i.e. a decrease in $a_{1}$ ). On the other hand, when income-rank comparison considerations are at work (as formalized in Section 2.1) we should observe similar responses for risk taking comparing the control treatment Social Uncorr to treatment Social and Predictions 1 and 2 should still hold. ${ }^{63,64}$ Thus, comparing treatment Social Uncorr to Social, we expect no significant difference in $a_{1}$.

We estimate a similar model as presented in equation (9) of Section 3.1 on observations from treatment Social and Social Uncorr. In a first step, we do not separate situations of lotteries with more upside and lotteries with more downside probability mass (no interaction term) and focus plainly on the treatment effect. We find no significant difference in risk taking between the treatments, suggesting that the distance in incomes does not explain our results (see specification (1) in Table A.5 in Appendix A.1). ${ }^{65}$ We can further investigate the treatment effect of social comparisons by comparing the control treatment Social Uncorr to treatment Alone. We apply similar specifications as presented in Table 2 in Section 3.1. Compared to the outcomes in Section 3.1 the effects are of the same sign, however, of lower magnitude and indistinguishable from zero (see Table A.6 in Appendix A.1). Furthermore, when we run estimations on subsamples based on gender (more or less similar subjects) we find again similar results. We estimate similar specifications as presented in Section 3.1 on observations from treatments Social Uncorr and Alone. For female subjects and femalefemale pairs the coefficients of SocialUncorr and SocialUncorr $\times I_{\text {LeftS }}$ are of the same sign but of slightly smaller magnitude compared to Section 3.1 (see Table A.7 in Appendix A.1). Comparison considerations lead to significantly lower risk taking for lotteries with more downside probability mass, whereas we find no significant treatment effect in case of lotteries with more upside probability mass. In contrast to Section 3.1, we generally find no significant

\footnotetext{
${ }^{63}$ See Appendix B.2 for a derivation of this claim.

${ }^{64}$ This prediction holds for all cases but the corner-case $a_{1}=a_{2}=0$. Recall that $a_{2}$ is a continuous random variable, and thus, $a_{2}=0$ is a zero-probability event.

${ }^{65}$ The coefficient SocialUncorr is insignificant (specification (1), Table A.5). Similarly, we find no significant difference between the treatments Social Uncorr. and Social when we estimate all other specifications as presented in Table 2 in Section 3.1 (results are reported in Table A.5 in Appendix A.1).
} 
treatment effect for male-male gender pairs anymore, neither for lotteries with more downside nor for lotteries with more upside probability mass. In summary, estimations based on the control treatment Social Uncorr provide no evidence for other forms of comparison concerns explaining the asymmetric findings of Section 3.1. Generally, results appear to be in line but weaker compared to Section 3.1.

Result 5 In situations of uncorrelated risky returns: the effect of comparison considerations on risk taking is weaker. For female subjects we find similar effects of lower magnitude compared to the situation of correlated risky returns that are stronger when the reference subject is also female (female-female pairs). For male subjects we find no significant comparison effect on risk taking.

Overall, the control treatment provides results supporting the findings in Section 3.1: social comparisons induce subjects to take less risk in case of lotteries with more downside probability mass but we find no significant effect in situations of lotteries with more upside probability mass. Preferences for the distance of incomes, and thus, also social loss aversion, seem not to be driving the asymmetric responses for different lotteries. What else could explain the asymmetric result? One possible interpretation is that subjects perceive payoffs of a similar range as "almost" identical. As by construction possible payoff differences are considerably smaller for lotteries with more upside probability mass compared to lotteries with more downside probability mass, subjects might perceive these payoff differences as negligible, and thus, we do not measure comparison effects. Put differently, to trigger an empirically measurable reaction larger payoff differences are necessary (as it is the case in situations of lotteries with more downside probability mass). This interpretation is in its nature related to the idea of income-distance based preferences in that there might be an implicit threshold in the distance of income so that subjects feel to be ahead or behind in rank.

\section{Conclusion}

We investigate the effect of social comparisons on risk taking inspired by the theoretical contributions of Robson (1992) and Konrad and Lommerud (1993). Our model predicts that income-rank-dependent preferences lead to less (more) risk taking in situations of lotteries with more downside (upside) probability mass. We find evidence of income comparisons affecting risk taking decisions. In line with our theoretical predictions, individuals take significantly less risk in situations of lotteries with more downside probability mass. We do

not find a significant effect for lotteries with more upside probability mass. Individuals who 
face a reference subject of the same gender exhibit a larger comparison effect on risk taking. We interpret this finding as evidence for Festinger's (1954) idea that individuals prefer to compare themselves to more rather than to less similar subjects.

The asymmetric finding for lotteries with more downside and lotteries with more upside probability mass comes as a surprise. A further control treatment provides no evidence that other forms of income comparisons, such as the distance in incomes or social loss aversion, can explain the asymmetric effect. Our favored explanation is that subjects might perceive situations in which income of others is expected to fall not far apart from their own income as "almost equal". In our setup, lotteries with more upside probability mass offer by construction with a high probability no large difference in the income of subjects, contrary to lotteries with more downside probability mass. This comparably small difference might be too small to trigger an empirically measurable response.

Overall, we find that social comparisons affect risk taking behavior. Our results give guidance where we should expect social comparison effects on risk taking: Comparison effects particularly emerge for lotteries with more downside than upside probability mass that are commonly positively skewed. Skewed distributions are applicable in various situations, such as in financial and insurance markets, a natural environment for risk taking decisions. ${ }^{66}$ Furthermore, our finding of reinforced comparison effects for more similar individuals implies that some industries and occupational fields are more prone to comparison effects on risk taking than others. Effects can be expected to be stronger when managers and employees are predominantly of the same gender, such as in the financial sector or in human resources related positions.

\footnotetext{
${ }^{66}$ For an overview see Adcock et al. (2015).
} 


\section{References}

[1] Adcock, C., Eling, M., and N. Loperfido, 2015, Skewed distributions in finance and actuarial science: A review, European Journal of Finance, 21(13-14), 1253-1281.

[2] Bault, N., Coricelli, G., and A. Rustichini, 2008, Interdependent utilities: How social ranking affects choice behavior, PLoS One, 3(10), 3477.

[3] Bault, N., Joffily, M., Rustichini, A., and G. Coricelli, and , 2011, Medial prefrontal cortex and striatum mediate the influence of social comparison on the decision process, Proc. Natl. Acad. Sci. U.S.A, 108(38), 16044-16049

[4] Becker, S.G., Murphy, K.M., and I. Werning, 2005, The equilibrium distribution of income and the market for status, Journal of Political Economy, 113(2), 282-310.

[5] Bereby-Meyer, Y., and A.E. Roth, 2006, The speed of learning in noisy games: Partial reinforcement and the sustainability of cooperation, American Economic Review, 96(4), 1029-1042.

[6] Bilancini, E., and L. Boncinelli, 2008, Ordinal vs cardinal status: Two examples, Economics Letters, 101(1), 17-19.

[7] Bolton, G.E., Brandts, J., and A. Ockenfels, 2005, Fair procedures: Evidence from games involving lotteries, Economic Journal, 115(506), 1054-1076.

[8] Bolton, G.E., and A. Ockenfels, 2010, Betrayal aversion: Evidence from Brazil, China, Oman, Switzerland, Turkey, and the United States: Comment, American Economic Review, 100(1), 628-633.

[9] Bolton, G.E., Ockenfels, A., and J. Stauf, 2015, Social responsibility promotes conservative risk behavior, European Economic Review, 74, 109-127.

[10] Bougheas, S., Nieboer, J., and M. Sefton, 2013, Risk-taking in social settings: Group and peer effects, Journal of Economic Behavior and Organization, 92, 273-283.

[11] Brennan, G., González, L.G., Güth, W., and M.V. Levati, 2008, Attitudes toward private and collective risk in individual and strategic choice situations, Journal of Economic Behavior and Organization, 67(1), 253-262.

[12] Camerer, C.F., and H. Kunreuther, 1989, Decision processes for low probability events: policy implications, Journal of Policy Analysis and Management, 8(4), 565-592. 
[13] Cappelen, A.W., Konow, J., Sørensen, E.Ø., and B. Tungodden, 2013, Just luck: An experimental study of risk-taking fairness, American Economic Review, 103(4), 13981413.

[14] Charness, G., and U. Gneezy, 2010, Portfolio choice and risk attitudes: An experiment, Economic Inquiry, 48(1), 133-146.

[15] Charness, G., and U. Gneezy, 2012, Strong evidence for gender differences in risk taking, Journal of Economic Behavior and Organization, 83(1), 50-58.

[16] Clark, A.E., Frijters, P., and M.A. Shields, 2008, Relative income, happiness, and utility: An explanation for the easterlin paradox and other puzzles, Journal of Economic Literature, 46(1), 95-144.

[17] Clark, A.E., and A.J. Oswald, 1996, Satisfaction and comparison income, Journal of Public Economics, 61(3), 359-381.

[18] Clark, A.E., Westergard-Nielsen, N., and N. Kristensen, 2009, Economic Satisfaction and Income Rank in Small Neighbourhoods, Journal of European Economic Association, $7(2-3), 519-527$.

[19] Cooper, D.J., and M. Rege, 2011, Misery loves company: Social regret and social interaction effects in choices under risk and uncertainty, Games and Economic Behavior, 73(1), 91-110.

[20] Dijk, O., Holmen, M., and M. Kirchler, 2014, Rank matters - The impact of social competition on portfolio choice, European Economic Review, 66, 97-110.

[21] Dohmen, T., Falk, A., Huffman, D., Sunde, U., Schupp, J., and G.G. Wagner, 2011, Individual risk attitudes: Measurement, determinants, and behavioral consequences, Journal of European Economic Association, 9(3), 522-550.

[22] Duesenberry, J.S., 1949, Income, saving and the theory of consumer behavior, Cambridge MA: Harvard University Press.

[23] Easterlin, R.A., 1995, Will raising incomes of all improve the happiness of all?, Journal of Economic Behavior and Organization, 27(1), 35-47.

[24] Fehr, E., and K.M. Schmidt, 2006, The economics of fairness, reciprocity and altruism experimental evidence and new theories, Handbook of the economics of giving, altruism and reciprocity, 1, 615-691. 
[25] Ferrer-i-Carbonell, A., 2005, Income and well-being: an empirical analysis of the comparison income effect, Journal of Public Economics, 89(5), 997-1019.

[26] Ferrer-i-Carbonell, A., and P. Frijters, 2004, How important is methodology for the estimates of the determinants of happiness?, Economic Journal, 114(497), 641-659.

[27] Festinger, L., 1954, A theory for social comparison processes, Human Relations, 7(2), 117-140.

[28] Fischbacher, U., 2007, Z-tree: Zurich tool box for ready-made economic experiments, Experimental Economics, 10(2), 171-178.

[29] Frank, R.H., 1985, The demand for unobservable and other nonpositional goods,. American Economic Review, 75(1), 101-116.

[30] Frank, R.H., 2008, Should public policy respond to positional externalities?, Journal of Public Economics, 92(8), 1777-1786.

[31] Frank, R.H., 2013, Falling behind: How rising inequality harms the middle class, vol. 4, Berkeley and Los Angeles CA: University of California Press.

[32] Friedl, A., De Miranda, K.L., and U. Schmidt, 2014, Insurance demand and social comparison: An experimental analysis, Journal of Risk and Uncertainty, 48(2), 97-109.

[33] Garrett, T.A., and R.S. Sobel, 1999, Gamblers favor skewness, not risk: Further evidence from United States' lottery games, Economics Letters, 63(1), 85-90.

[34] Gneezy, U., and J. Potters, 1997, An experiment on risk taking and evaluation periods, Quarterly Journal of Economics, 112(2), 631-645.

[35] Golec, J., and M. Tamarkin, 1998, Bettors love skewness, not risk, at the horse track, Journal of Political Economy, 106(1), 205-225.

[36] Greiner, B., 2004, An Online Recruitment System for Economic Experiments. In: Kurt Kremer, Volker Macho (eds.): Forschung und wissenschaftliches Rechnen 2003. GWDG Bericht 63, Göttingen: Ges. für Wiss. Datenverarbeitung, 79-93.

[37] Grimm, S., Kocher, M.G., Krawczyk, M., and F. Le Lec, 2015, Sharing or gambling? On risk attitudes in social contexts, Mimeo.

[38] Grossman, P.J., and C.C. Eckel, 2015, Loving the long shot: Risk taking with skewed lotteries, Journal of Risk and Uncertainty, 51(3), 195-217. 
[39] Güth, W., Levati, M.V., and M. Ploner, 2008, On the social dimension of time and risk preferences: An experimental study, Economic Inquiry, 46(2), 261-272.

[40] Holt, C., and S.K. Laury, 2002, Risk aversion and incentive effects, American Economic Review, 92(5), 1644-1655.

[41] Kahneman, D., and A. Tversky, 1979, Prospect theory: An analysis of decision under risk, Econometrica, 47(2), 263-291.

[42] Konrad, K.A., and K.E. Lommerud, 1993, Relative standing comparisons, risk taking, and safety regulations, Journal of Public Economics, 51(3), 345-358.

[43] Krawczyk, M., and F. Le Lec, 2010, 'Give me a chance!' An experiment in social decision under risk, Experimental Economics, 13(4), 500-511.

[44] Lahno, A.M., and M. Serra-Garcia, 2015, Peer effects in risk taking: Envy or conformity?, Journal of Risk and Uncertainty, 50(1), 73-95.

[45] Linde, J., and J. Sonnemans, 2012, Social comparison and risky choices, Journal of Risk and Uncertainty, 44(1), 45-72.

[46] Luttmer, E.F.P., 2005, Neighbors as negatives: relative earnings and well-being, Quarterly Journal of Economics, 120(3), 963-1002.

[47] McBride, M., 2001, Relative-income effects on subjective well-being in the cross-section, Journal of Economic Behaviour and Organization, 45(3), 251-278.

[48] Menezes, C., Geiss, C., and J. Tressler, 1980, Increasing downside risk, American Economic Review, 70(5), 921-932.

[49] Quandt, R.E., 1986, Betting and Equilibrium, Quarterly Journal of Economics, 101(), 201-207.

[50] Rabin, M., and G. Weizsäcker, 2009, Narrow bracketing and dominated choices, American Economic Review, 99(4), 1508-1543.

[51] Robson, A.J., 1992, Status, the distribution of wealth, private and social attitudes to risk, Econometrica, 60(4), 837-857.

[52] Rohde, I.M.T., and K.I.M. Rohde, 2011, Risk attitudes in a social context, Journal of Risk and Uncertainty, 43(3), 205-225. 
[53] Schubert, R., Brown, M., Gysler, M., and H.W. Brachinger, 1999, Financial decisionmaking: Are women really more risk-averse?, American Economic Review, 89(2), 381385 .

[54] Schwerter, F., 2013, Social reference points and risk taking, Bonn Econ Discussion Papers, No. 11.

[55] Sobel, J., 2005, Interdependent preferences and reciprocity, Journal of Economic Literature, 43(2), 392-436.

[56] Sutter, M., 2007, Are teams prone to myopic loss aversion? An experimental study on individual versus team investment behavior, Economics Letters, 97(2), 128-132.

[57] Trautmann, S.T., and F.M. Vieider, 2012, Social influences on risk attitudes: Applications in economics, In Handbook of risk theory, 575-600, Heidelberg: Springer Verlag.

[58] Veblen, T., 1899, The theory of the leisure class (reprinted 1953, Mentor Books, New York).

[59] Viscusi, W.K., Phillips, O.R., and S. Kroll, 2011, Risky investment decisions: How are individuals influenced by their groups?, Journal of Risk and Uncertainty, 43(2), 81-106. 


\section{A Appendix}

\begin{tabular}{|c|c|c|c|c|}
\hline Treatments & Alone & Social & $\begin{array}{c}\text { Alone } \\
\text { Passive }\end{array}$ & $\begin{array}{l}\text { Social } \\
\text { Uncorr }\end{array}$ \\
\hline \# Sessions & 45 & 45 & 18 & 44 \\
\hline \multicolumn{5}{|l|}{ Participants } \\
\hline \# Active & 45 & 45 & - & 44 \\
\hline \# Passive & - & 45 & 18 & 44 \\
\hline \multicolumn{5}{|l|}{ Observations per participant ${ }^{a}$} \\
\hline \# Downside prob. lotteries & 4 & 4 & 4 & 4 \\
\hline \# Upside prob. lotteries & 4 & 4 & 4 & 4 \\
\hline
\end{tabular}

Note: In treatments Alone and Alone Passive in each session one subject participates. In treatment Social and Social Uncorr in each session one active and one passive subject participate simultaneously. Treatments Alone, Social, Alone Passive are explained in Section 3.1, details on the control treatment Social Uncorr are presented in Section 3.3.

Table A.1: Summary of the experimental treatments 


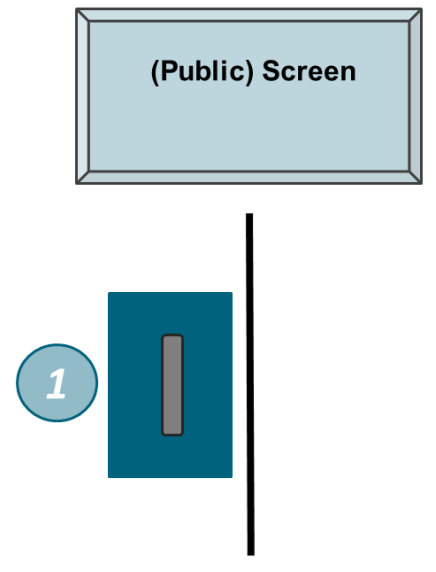

Treatment Alone

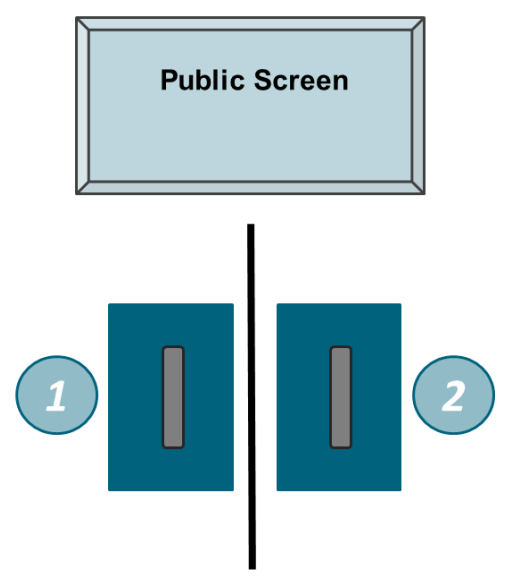

Treatment Social

Note: In treatment Alone participates one, in treatment Social two subjects in each session. Subjects in treatment Social are separated by a room divider to ensure privacy, while both subjects observe the identical "public screen" that shows the payoff-relevant portfolio choice (i.e. subject (1) looks to her left, subject (2) to her right).

Figure A.1: Laboratory setup 


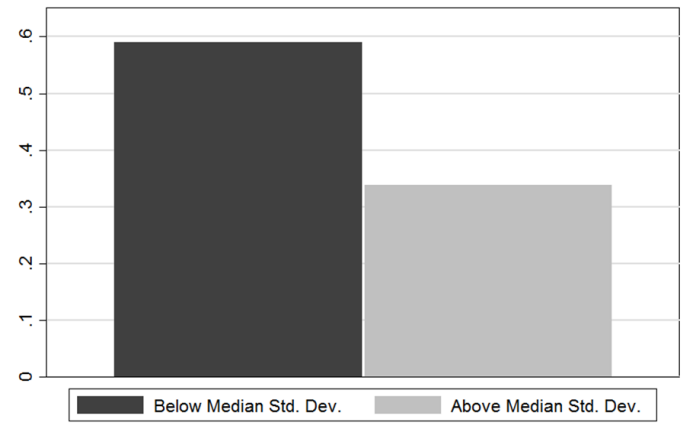

Risk share: Above and nelow median std. dev. lotteries

Note: "Risk share" refers to the share of the endowment that subjects invest into the risky lottery, taking values between $0(0 \%)$ and $1(100 \%)$.

Figure A.2: Risk share of above and below median std. dev. lotteries

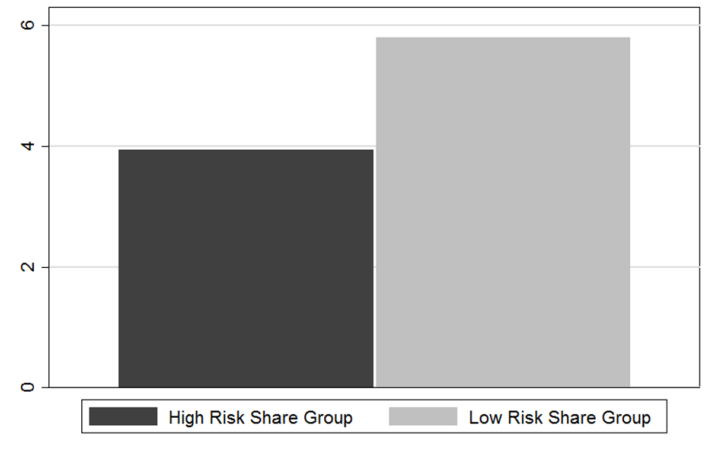

Above median std. dev. lotteries

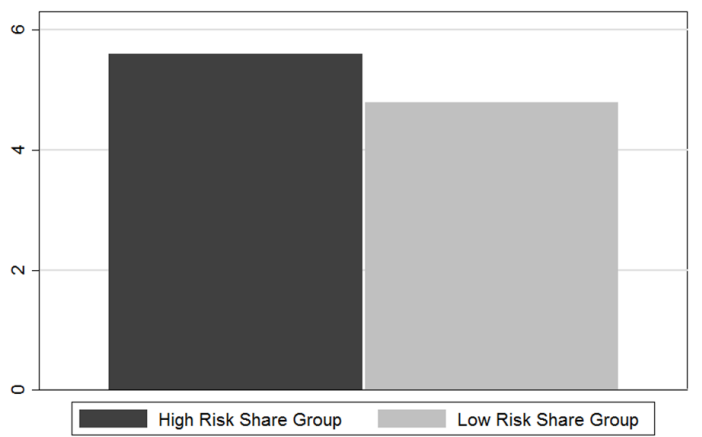

Below median std. dev. lotteries

Note: Passive subjects are randomly assigned into two groups: receiving high risk shares (high-risk group) or low risk shares (low-risk group). Assuming that subjects are risk averse one can reasonably expect that in situations of high risk (above-median std. dev. lotteries) high-risk-group subjects are less satisfied than low-risk-group subjects. Similarly, in situations of low risk (below-median std. dev. lotteries) low-risk-group subjects are expected to be less satisfied than high-risk-group subjects.

Figure A.3: Satisfaction of passive subjects in situations of more or less risk 


\begin{tabular}{lccccccc}
\hline \hline & \multirow{2}{*}{ Alone } & \multirow{2}{*}{ Social } & Social & \multicolumn{4}{c}{ Total } \\
& & & Uncorr & & \multicolumn{3}{c}{} \\
\cline { 5 - 8 } & Mean & Mean & Mean & Mean & S.D. & Min & Max \\
\hline Risk share & 0.50 & 0.44 & 0.52 & 0.48 & 0.32 & 0 & 1 \\
Downside prob. & 0.39 & 0.30 & 0.38 & 0.61 & 0.31 & 0 & 1 \\
Upside prob. & 0.62 & 0.57 & 0.64 & 0.36 & 0.30 & 0 & 1 \\
& & & & & & & \\
Satisfaction & 6.7 & 7.0 & 7.0 & 6.9 & 2.2 & 0 & 10 \\
$\quad$ Downside prob. & 6.3 & 6.8 & 6.8 & 6.6 & 2.2 & 0 & 10 \\
Upside prob. & 7.1 & 7.0 & 7.1 & 7.0 & 2.1 & 0 & 10 \\
& & & & & & & \\
Male & 0.49 & 0.45 & 0.64 & 0.53 & 0.50 & 0 & 1 \\
Age & 23.8 & 24.3 & 25.3 & 24.5 & 6.2 & 18 & 60 \\
Econ & 0.13 & 0.25 & 0.18 & 0.19 & 0.39 & 0 & 1 \\
\hline \hline
\end{tabular}

Note: Descriptive statistics for all 134 subjects that actively choose their investment. "Risk share" refers to the share of invested endowment into the risky project (lottery) that takes a value between 0 and $1,1(0)$ when $100 \%$ (0\%) is invested into the lottery. "Male" takes a value of 1 for male subjects. Econ takes a value of 1 for subjects that study in business related fields such as economics. "Downside prob." refers to lotteries with more downside probability mass while "upside prob." refers to lotteries with more upside probability mass.

Table A.2: Summary statistics of actively investing subjects 


\begin{tabular}{|c|c|c|c|c|c|c|c|}
\hline & Alone & Social & $\begin{array}{l}\text { Social } \\
\text { Uncorr }\end{array}$ & \multicolumn{4}{|c|}{ Total } \\
\hline & Mean & Mean & Mean & Mean & S.D. & Min & $\operatorname{Max}$ \\
\hline \multicolumn{8}{|l|}{ High-risk group } \\
\hline Risk share & 0.81 & 0.81 & 0.81 & 0.81 & 0.09 & 0.62 & 0.95 \\
\hline Downside prob. & 0.78 & 0.78 & 0.78 & 0.78 & 0.12 & 0.62 & 0.95 \\
\hline Upside prob. & 0.82 & 0.82 & 0.82 & 0.82 & 0.05 & 0.77 & 0.89 \\
\hline Satisfaction & 4.48 & 4.89 & 4.42 & 4.75 & 2.59 & 0 & 10 \\
\hline Downside prob. & 4.03 & 3.85 & 2.09 & 3.44 & 2.40 & 0 & 9 \\
\hline Upside prob. & 5.50 & 5.69 & 6.41 & 5.82 & 2.32 & 1 & 10 \\
\hline \multicolumn{8}{|l|}{ Low-risk group } \\
\hline Risk share & 0.21 & 0.21 & 0.21 & 0.21 & 0.10 & 0.05 & 0.39 \\
\hline Downside prob. & 0.22 & 0.22 & 0.22 & 0.22 & 0.07 & 0.13 & 0.30 \\
\hline Upside prob. & 0.22 & 0.22 & 0.22 & 0.22 & 0.13 & 0.05 & 0.39 \\
\hline Satisfaction & 6.11 & 4.99 & 5.04 & 5.12 & 2.85 & 0 & 10 \\
\hline Downside prob. & 6.19 & 5.70 & 5.87 & 5.83 & 2.70 & 0 & 10 \\
\hline Upside prob. & 6.16 & 4.46 & 4.48 & 4.64 & 2.87 & 0 & 10 \\
\hline Male & 0.78 & 0.50 & 0.59 & 0.58 & 0.49 & 0 & 1 \\
\hline Age & 22.4 & 23.8 & 23.1 & 23.3 & 3.8 & 18 & 39 \\
\hline Econ & 0.11 & 0.16 & 0.18 & 0.16 & 0.37 & 0 & 1 \\
\hline
\end{tabular}

Note: Descriptive statistics for all 107 passive subjects. "Passive" refers to the share of risky investment being randomly drawn from a distribution. Two groups are implemented with different distributions applying for the randomly drawn risk share. In a first step, the empirical distribution of risk shares for each lottery from the first 10 active subjects is recorded. This empirical distribution is used to determine the randomly drawn passive risk shares that are identical for subjects of the same group in each treatment. "High-risk group" refers to a situation where the passive risk share is a random draw from right end outside the $95 \%$ confidence interval of the empirical distribution of risk shares for each lottery. "Low-risk group" refers to a situation where the passive risk share is a random draw from the left end outside the $95 \%$ confidence interval of the empirical distribution of risk shares for each lottery. "Risk share" refers to the share of endowment invested in the risky project (lottery) and takes a value of $1(0)$ when $100 \%(0 \%)$ is invested into the lottery. "Male" takes a value of 1 for male subjects. Econ takes a value of 1 for subjects that study in business related fields such as economics. "Downside prob." refers to lotteries with more downside probability mass while "Upside prob." refers to lotteries with more upside probability mass.

Table A.3: Summary statistics for passive subjects 


\begin{tabular}{|c|c|c|}
\hline & $\begin{array}{c}\text { Downside } \\
\text { probability mass } \\
\text { lotteries } \\
(1) \\
\text { risk share }\end{array}$ & $\begin{array}{c}\text { Upside } \\
\text { probability mass } \\
\text { lotteries } \\
(2) \\
\text { risk share }\end{array}$ \\
\hline Social & $\begin{array}{c}-0.191^{* * *} \\
(0.039)\end{array}$ & $\begin{array}{l}-0.059 \\
(0.053)\end{array}$ \\
\hline Social $\times I_{\text {different_gender }}$ & $\begin{array}{l}0.191^{* *} \\
(0.074)\end{array}$ & $\begin{array}{c}0.027 \\
(0.069)\end{array}$ \\
\hline Constant & $\begin{array}{c}0.384^{* * *} \\
(0.034)\end{array}$ & $\begin{array}{c}0.615^{* * *} \\
(0.032)\end{array}$ \\
\hline $\begin{array}{l}\text { Individual } \\
\text { controls }\end{array}$ & No & No \\
\hline $\begin{array}{l}\text { Time and sequence } \\
\text { fixed effects }\end{array}$ & No & No \\
\hline$N$ & 336 & 336 \\
\hline Clusters & 84 & 84 \\
\hline
\end{tabular}

Note: Random effects panel regression model. Dependent variable: share invested into the risky lottery. Standard errors in parentheses, ${ }^{*} \mathrm{p}<0.10,{ }^{* *} \mathrm{p}<0.05,{ }^{* * *} \mathrm{p}<0.01$. Specification (1) applies a subsample of lotteries with more downside probability mass while specification (2) a subsample of lotteries with more upside probability mass. Idifferent_gender is an indicator variable that takes a value of 1 for participants grouped to another participant of a different gender in treatment Social and a value of 0 for a pair of participants of the same gender.

Table A.4: Same-gender and different-gender pairs 


\section{A.1 Results for uncorrelated lottery returns}

\begin{tabular}{|c|c|c|c|c|}
\hline & $\begin{array}{c}\text { All } \\
\text { asymmetric } \\
\text { lotteries } \\
(1) \\
\text { risk share }\end{array}$ & $\begin{array}{c}\text { All } \\
\text { asymmetric } \\
\text { lotteries } \\
(2) \\
\text { risk share }\end{array}$ & $\begin{array}{c}\text { More } \\
\text { asymmetric } \\
\text { lotteries } \\
(3) \\
\text { risk share }\end{array}$ & $\begin{array}{c}\text { Less } \\
\text { asymmetric } \\
\text { lotteries } \\
(4) \\
\text { risk share }\end{array}$ \\
\hline SocialUncorr & $\begin{array}{c}0.052 \\
(0.034)\end{array}$ & $\begin{array}{c}0.057 \\
(0.050)\end{array}$ & $\begin{array}{c}0.072 \\
(0.064)\end{array}$ & $\begin{array}{c}0.042 \\
(0.049)\end{array}$ \\
\hline$I_{\text {upside }}$ & & $\begin{array}{c}0.258^{* * *} \\
(0.038)\end{array}$ & $\begin{array}{c}0.407^{* * *} \\
(0.064)\end{array}$ & $\begin{array}{c}0.190^{* * *} \\
(0.038)\end{array}$ \\
\hline $\begin{array}{l}\text { SocialUncorr } \\
\times I_{\text {upside }}\end{array}$ & & $\begin{array}{l}-0.010 \\
(0.060)\end{array}$ & $\begin{array}{c}0.013 \\
(0.086)\end{array}$ & $\begin{array}{l}-0.034 \\
(0.062)\end{array}$ \\
\hline risk aversion $i$ & $\begin{array}{c}-0.034^{* * *} \\
(0.011)\end{array}$ & $\begin{array}{c}-0.034^{* * *} \\
(0.011)\end{array}$ & $\begin{array}{c}-0.038^{* * *} \\
(0.013)\end{array}$ & $\begin{array}{c}-0.030^{* * *} \\
(0.008)\end{array}$ \\
\hline Constant & $\begin{array}{c}0.542^{* * *} \\
(0.123)\end{array}$ & $\begin{array}{c}0.358^{* * *} \\
(0.127)\end{array}$ & $\begin{array}{l}0.358^{* *} \\
(0.170)\end{array}$ & $\begin{array}{c}0.336^{* * *} \\
(0.126\end{array}$ \\
\hline $\begin{array}{l}\text { Individual } \\
\text { controls }\end{array}$ & Yes & Yes & Yes & Yes \\
\hline $\begin{array}{l}\text { Time and sequence } \\
\text { fixed effects }\end{array}$ & Yes & Yes & Yes & Yes \\
\hline$N$ & 648 & 648 & 324 & 324 \\
\hline Clusters & 81 & 81 & 81 & 81 \\
\hline
\end{tabular}

Note: Random effects panel regression model. Dependent variable: risk share. Standard errors in parentheses, ${ }^{*} \mathrm{p}<0.10,{ }^{* *} \mathrm{p}<0.05,{ }^{* * *} \mathrm{p}<0.01$. I upside is an indicator variable that takes a value of 1 for lotteries with more upside probability mass and zero otherwise. SocialUncorr is an indicator variable that takes a value of 1 for observations in treatment Social Uncorr and zero otherwise. Specifications (1) and (2) include all observations of asymmetric lotteries (more downside or upside probability mass) from treatments Social and Social Uncorr. Specification (3) includes the subsample of more asymmetric lotteries $\left(\mathrm{L}_{5}, \mathrm{~L}_{6}, \mathrm{~L}_{7}, \mathrm{~L}_{8}\right.$ in Table (1)). Specification (4) includes the subsample of less asymmetric lotteries $\left(\mathrm{L}_{1}, \mathrm{~L}_{2}, \mathrm{~L}_{3}, \mathrm{~L}_{4}\right.$ in Table (1)). "Individual controls" include gender, age, whether the field of study is business related, risk aversion, impulsivness and patience, enviousness, a dummy whether subjects participted in laboratory expermints before. "Time and sequence fixed effects" include round fixed effects and a dummy for the sequence in which lotteries are shown.

Table A.5: Comparisons and risk taking for correlated vs. uncorrelated lottery returns 


\begin{tabular}{lcccc}
\hline \hline & $\begin{array}{c}\text { All } \\
\text { asymmetric } \\
\text { lotteries }\end{array}$ & $\begin{array}{c}\text { All } \\
\text { asymmetric } \\
\text { lotteries }\end{array}$ & $\begin{array}{c}\text { More } \\
\text { asymmetric } \\
\text { lotteries }\end{array}$ & $\begin{array}{c}\text { Less } \\
\text { asymmetric } \\
\text { lotteries }\end{array}$ \\
& risk share & risk share & risk share & $(4)$ \\
& -0.010 & -0.036 & -0.052 & -0.020 \\
SocialUncorr & $(0.054)$ & $(0.054)$ & $(0.067)$ & $(0.058)$ \\
& $0.231^{* * *}$ & $0.216^{* * *}$ & $0.324^{* * *}$ & $0.173^{* * *}$ \\
$I_{\text {upside }}$ & $(0.045)$ & $(0.044)$ & $(0.068)$ & $(0.042)$ \\
SocialUncorr & 0.031 & 0.033 & 0.080 & -0.015 \\
$\times I_{\text {upside }}$ & $(0.063)$ & $(0.064)$ & $(0.089)$ & $(0.064)$ \\
risk aversion & & -0.019 & -0.014 & $-0.023^{*}$ \\
Constant & & $(0.012)$ & $(0.014)$ & $(0.013)$ \\
\hline Individual & $0.384^{* * *}$ & $0.404^{* * *}$ & $0.522^{* * *}$ & $0.307^{* * *}$ \\
controls & $(0.034)$ & $(0.099)$ & $(0.141)$ & $(0.104)$ \\
Time and sequence & No & Yes & Yes & Yes \\
fixed effects & No & Yes & Yes & Yes \\
\hline$N$ & 680 & 680 & 340 & 340 \\
Clusters & 85 & 85 & 85 & 85 \\
\hline \hline
\end{tabular}

Note: Random effects panel regression model. Dependent variable:risk share. Standard errors in parentheses, ${ }^{*} \mathrm{p}<0.10,{ }^{* *} \mathrm{p}<0.05,{ }^{* *} \mathrm{p}<0.01 . I_{\text {upside }}$ is an indicator variable that takes a value of 1 for lotteries with more upside probability mass and zero otherwise. SocialUncorr is an indicator variable that takes a value of 1 for observations in treatment Social Uncorr and zero otherwise. Specifications (1) and (2) include all observations of asymmetric lotteries from treatments Alone and Social Uncorr (i.e. lotteries with more downside or upside probability mass). Specification (3) includes the subsample of more asymmetric lotteries ( $\mathrm{L}_{5}, \mathrm{~L}_{6}, \mathrm{~L}_{7}, \mathrm{~L}_{8}$ in Table (1)). Specification (4) includes the subsample of less asymmetric lotteries ( $\mathrm{L}_{1}$, $\mathrm{L}_{2}, \mathrm{~L}_{3}, \mathrm{~L}_{4}$ in Table (1)). "Individual controls" include gender, age, whether the field of study is business related, risk aversion, impulsivness and patience, enviousness, a dummy whether subjects participted in laboratory expermints before. "Time and sequence fixed effects" include round fixed effects and a dummy for the sequence in which lotteries are shown.

Table A.6: Comparisons and risk taking for uncorrelated lottery returns 


\begin{tabular}{|c|c|c|c|c|}
\hline ^ & $\begin{array}{c}\text { Female } \\
\text { with } \\
\text { Female } \\
(1) \\
\text { risk share }\end{array}$ & $\begin{array}{c}\text { Male } \\
\text { with } \\
\text { Male } \\
(2) \\
\text { risk share }\end{array}$ & $\begin{array}{c}\text { Female } \\
(3) \\
\text { risk share }\end{array}$ & $\begin{array}{c}\text { Male } \\
(4) \\
\text { risk share }\end{array}$ \\
\hline SocialUncorr & $\begin{array}{c}-0.155^{* *} \\
(0.076)\end{array}$ & $\begin{array}{c}0.128 \\
(0.095)\end{array}$ & $\begin{array}{c}-0.130^{* *} \\
(0.058)\end{array}$ & $\begin{array}{c}0.061 \\
(0.082)\end{array}$ \\
\hline$I_{\text {upside }}$ & $\begin{array}{c}0.186^{* * *} \\
(0.065)\end{array}$ & $\begin{array}{c}0.276^{* * *} \\
(0.063)\end{array}$ & $\begin{array}{c}0.186^{* * *} \\
(0.064)\end{array}$ & $\begin{array}{c}0.276^{* * *} \\
(0.063)\end{array}$ \\
\hline $\begin{array}{l}\text { SocialUncorr } \\
\times I_{\text {upside }}\end{array}$ & $\begin{array}{c}0.150 \\
(0.168)\end{array}$ & $\begin{array}{l}-0.076 \\
(0.0956)\end{array}$ & $\begin{array}{c}0.107 \\
(0.093)\end{array}$ & $\begin{array}{l}-0.032 \\
(0.086)\end{array}$ \\
\hline Constant & $\begin{array}{c}0.389^{* * *} \\
(0.035) \\
\end{array}$ & $\begin{array}{c}0.379^{* * *} \\
(0.058) \\
\end{array}$ & $\begin{array}{c}0.389^{* * *} \\
(0.035) \\
\end{array}$ & $\begin{array}{c}0.379^{* * *} \\
(0.058) \\
\end{array}$ \\
\hline $\begin{array}{l}\text { Individual } \\
\text { controls }\end{array}$ & No & No & No & No \\
\hline $\begin{array}{l}\text { Time and sequence } \\
\text { fixed effects }\end{array}$ & No & No & No & No \\
\hline$N$ & 216 & 280 & 296 & 384 \\
\hline Clusters & 27 & 35 & 37 & 48 \\
\hline
\end{tabular}

Note: Random effects panel regression model. Dependent variable: share invested into the risky lottery. Standard errors in parentheses, ${ }^{*} \mathrm{p}<0.10,{ }^{* *} \mathrm{p}<0.05,{ }^{* * *} \mathrm{p}<0.01 . I_{\text {upside }}$ is an indicator variable that takes a value of 1 for lotteries with more upside probability mass and zero otherwise. SocialUncorr is an indicator variable that takes a value of 1 for observations in treatment Social Uncorr and zero otherwise. Genderspecific subsamples. Specifiations (1) and (2) focus on subsamples in which grouped subjects are of the same gender in treatment Social Uncorr and of the corresponding same gender in treatment Alone (female-female compared to female and male-male compared to male). Specifications (3) and (4) focus on gender without considering the gender of the other (reference) subject in treatment Social Uncorr.

Table A.7: Subjects of the same gender and uncorrelated lottery returns 


\section{B Mathematical derivations}

\section{B.1 Costs of deviating from the optimal investment without in- come comparisons}

Given an optimal investment allocation $a_{1}^{*}$ for the consumption part of the utility function $u\left(y_{1}\left(a_{1}\right)\right)$, we can define the constant $\bar{U}=u\left(y_{1}\left(a_{1}^{*}\right)\right)$. Thus the cost function defined in (5) of Section 2.1 can be stated as

$$
\begin{aligned}
C\left(a_{1}\right) & =\bar{U}-E\left[u\left(y_{1}\left(a_{1}\right)\right)\right] \\
& =\bar{U}-\left[p_{G} \times u\left(\theta_{G} a_{1}+\left(1-a_{1}\right)\right)+\left(1-p_{G}\right) \times u\left(1-a_{1}\right)\right] .
\end{aligned}
$$

Taking the first derivative with resepct to $a_{1}$ yields

$$
\frac{\partial C\left(a_{1}\right)}{\partial a_{1}}=-p_{G}\left(\theta_{G}-1\right) \times u^{\prime}\left(\theta_{G} a_{1}+\left(1-a_{1}\right)\right)+\left(1-p_{G}\right) \times u^{\prime}\left(1-a_{1}\right) .
$$

Considering the second derivative with respect to $a_{1}$ :

$$
\frac{\partial^{2} C\left(a_{1}\right)}{\partial a_{1}^{2}}=-p_{G}\left(\theta_{G}-1\right)^{2} \times u^{\prime \prime}\left(\theta_{G} a_{1}+\left(1-a_{1}\right)\right)-\left(1-p_{G}\right) \times u^{\prime \prime}\left(1-a_{1}\right) .
$$

From (12) we see that

$$
\frac{\partial^{2} C\left(a_{1}\right)}{\partial a_{1}^{2}}>0 \quad \text { if } \quad u^{\prime \prime}(\cdot)<0,
$$

and thus, assuming that subjects are risk averse for the standard part of the utility function (i.e. $u\left(y_{1}\left(a_{1}\right)\right)$ is strictly concave) is sufficient to ensure that the cost function $C\left(a_{1}\right)$ is convex.

B.1 


\section{B.2 Uncorrelated lottery returns and income-rank comparisons}

The following holds for all $a_{1}$ and $a_{1}$ but the corner case $a_{1}=a_{2}=0$. Analog to equation (6) in Section 2.1 the optimization problem for the situations when returns of risky lotteries are uncorrelated becomes

$$
\begin{aligned}
\max _{a_{1}} \pi_{1}= & p_{G}^{2} \times\left[F\left(a_{1}\right) W+\left(1-F\left(a_{1}\right)\right) L\right] \\
& +\left(1-p_{G}\right)^{2} \times\left[\left(1-F\left(a_{1}\right)\right) W+F\left(a_{1}\right) L\right]-C\left(a_{1}\right) \\
& +p_{G}\left(1-p_{G}\right) W+p_{G}\left(1-p_{G}\right) L .
\end{aligned}
$$

The last two terms of equation (13) refer to the comparison utility gain (loss) when the lottery of one subject pays the "good-state" return $\theta_{G}$ while the lottery of the other subjects pays 0 in the "bad-state". In these situations, independent of the subjects' investment

decisions, the subject receiving $\theta_{G}(0)$ will be ahead (behind), and thus, will receive utility from comparisons equal to $W(L)$. Solving problem (13) yields the first-order condition

$$
f\left(\widetilde{a}_{1}^{s}\right)\left[p_{G}^{2}(W-L)+\left(1-p_{G}\right)^{2}(L-W)\right]=C^{\prime}\left(\widetilde{a}_{1}^{s}\right)
$$

in which we define $\widetilde{a}_{1}^{s}$ as optimal investment when we incorporate social comparisons in case of uncorrelated lottery returns. We can further simplify (14) to

$$
f\left(\widetilde{a}_{1}^{s}\right)[W-L]\left[2 p_{G}-1\right]=C^{\prime}\left(\widetilde{a}_{1}^{s}\right) .
$$

Equation (15) is identical to equation (7) in Section 2.1 and it follows directly that $\widetilde{a}_{1}^{s}=a_{1}^{s}$. 


\section{Experimental instructions*}

\section{Welcome to the experiment!}

Please read this instruction carefully and completely. Thoroughly understanding this instruction will help you to earn more money. In the experiment, your earnings are measured in Taler. At the end of the experiment we will convert the Talers you earned into Euros and pay you accordingly. The conversion rate is: 25 Talers $=\mathbf{1}$ Euro. Additionally, each participant receives a show-up fee of 6 Euros.

We ensure your anonymity throughout the experiment. Please keep in mind that you are not allowed to communicate with other participants during the experiment. If you do not comply with this rule you will be asked to leave the laboratory without getting paid. In case you have a question before the experiment begins please raise your hand. Whenever you have a question at any time during the experiment please press the "help button" and we will help you.

\section{Your task:}

You will observe Project A and Project B on a common screen. Each participant receives 175 Taler that are fully invested into Project A and Project B. One participant decides for himself how he splits his endowment between Project A and Project B (0 to 175 Talers can be invested into a project). A random draw of the computer determines the split of the second participant's endowment between Project A and B. The roles of actively investing or of having the computer to decide are randomly assigned before the experiment starts and remain unchanged for the duration of the experiment.

Your earnings in the experiment depend on the investment decisions: each project exhibits multipliers (i.e. returns) multiplying the invested Talers. The two projects differ as follows:

- Project A offers two different multipliers of which just one will be chosen at the end of the experiment. One of the two multipliers leads to a higher payoff than the other. For each investment decision the common screen shows the probabilities that the high or the low multiplier is chosen.(See a stylized example for how project A works attached at the end of the instructions.)

- Project B offers a single multiplier of one; i.e. your investment into Project B will be paid to you one-to-one.

The realization of Project A (that is, whether the high or the low multiplier applies) will be simultaneously decided for all participants by the same dice rolls at the end of the experiment.

\footnotetext{
* The experiment was conducted in German. This appendix contains a translated version of the instructions for the treatment Social.
} 
After the investment decision (the random investment by the computer, respectively) each participant will answer the following question on their private screen:

How satisfied are you with your current Project A/ Project B-combination on a scale 0 (very dissatisfied) to 10 (highly satisfied)?

\section{Procedure}

Overall, you will repeat this task several times, and thus, invest several times in a Project A and Project B. At each point in time the active participant will decide on the investment anew and independent of the pervious decisions while the computer randomly draws a new investment decision for the passive participant. In order to proceed to the next Project A / Project B combination, a "Done" button appears on your screen after one minute. You do not need to click and proceed immediately. It is important to take your time for each decision.

At the end of the experiment the computer will randomly select one Project A / Project B combination for the payoff.

- The randomly selected Project A/ Project B combination will appear on the common screen.

- The experimenter will roll dice clearly visible for all using a dice cup under ample shaking. This dice roll determines the investment outcome for both participants. The experimenter will enter the result into the common screen.

- The computer calculates the payoff of Project A according to your investment decision and to the outcome of the dice rolls. Your final result for Project A and Project B of the selected investment decision will be summed up and displayed on your private screen.

Consequently, your earnings will be determined by the investment into Project A and Project $\mathrm{B}$ and by the dice rolls.

After the experiment we ask you to provide some further information. As a matter of course, all of your provided information will be treated anonymously.

Thank you very much for showing up and good luck! 


\section{Practice round}

Before the experiment starts you will participate in a practice round that will help you to better understand the experiment. The practice round is not relevant for the disbursement.

\section{Example for illustration:}

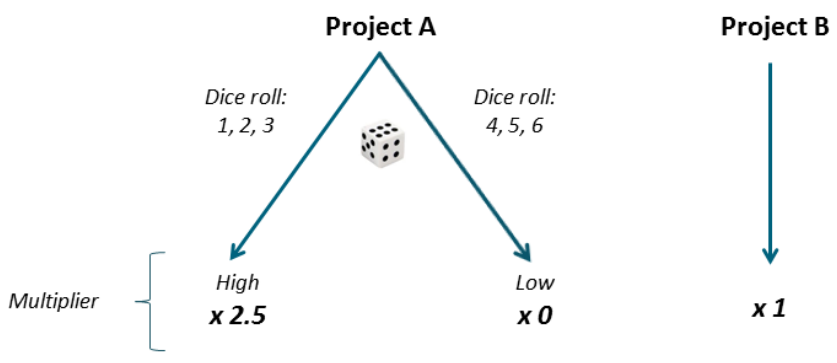

